Review

\title{
Recent Syntheses of 1,2,3,4-Tetrahydroquinolines, 2,3-Dihydro-4(1H)-quinolinones and 4(1H)-Quinolinones using Domino Reactions
}

\author{
Baskar Nammalwar and Richard A. Bunce * \\ Department of Chemistry, Oklahoma State University, Stillwater, OK 74078-3071, USA \\ * Author to whom correspondence should be addressed; E-Mail: rab@okstate.edu; \\ Tel: +1-405-744-5952; Fax: +1-405-744-6007.
}

Received: 2 December 2013; in revised form: 13 December 2013; Accepted: 20 December 2013 / Published: 24 December 2013

\begin{abstract}
A review of the recent literature is given focusing on synthetic approaches to 1,2,3,4-tetrahydroquinolines, 2,3-dihydro-4(1H)-quinolinones and 4(1H)-quinolinones using domino reactions. These syntheses involve: (1) reduction or oxidation followed by cyclization; (2) $\mathrm{S}_{\mathrm{N}}$ Ar-terminated sequences; (3) acid-catalyzed ring closures or rearrangements; (4) high temperature cyclizations and (5) metal-promoted processes as well as several less thoroughly studied reactions. Each domino method is presented with a brief discussion of mechanism, scope, yields, simplicity and potential utility.
\end{abstract}

Keywords: domino reaction; tandem reaction; cascade reaction; 1,2,3,4-tetrahydroquinoline; 2,3-dihydro-4(1H)-quinolinone; $4(1 H)$-quinolinone; heterocycle synthesis; drug synthesis

\section{Introduction}

Domino reactions, also known as tandem or cascade reactions, have emerged as a highly effective strategy for the synthesis of bioactive natural products and pharmaceutical agents [1]. These methods enable chemists to perform complex synthetic conversions with high efficiency using simple starting materials, often via a biomimetic pathway [2]. Thus, domino reactions contribute immensely to synthetic drug design strategies, enhance aesthetic approaches in total synthesis, and improve yields in large-scale synthesis $[1,2]$. The advantages of these methods include excellent atom economy, high selectivity, and less waste $[3,4]$. Additionally, using these strategies, multiple transformations can be carried out in a single laboratory operation without the isolation of intermediates making them prime 
examples of green chemistry [5,6]. Despite the widespread proliferation of domino reactions, researchers have continued to channel their efforts in this area as new structures with chiral architectures and novel substitution patterns are required.

The goal of this survey is to provide readers with a summary and critical evaluation of the domino strategy as it pertains to the synthesis of tetrahydroquinolines, 2,3-dihydro-4(1H)-quinolinones and $4(1 H)$-quinolinones. We do not seek to provide a comprehensive treatise on methods to generate these heterocyclic scaffolds but rather to highlight the application of domino strategies for their preparation. Other, more expansive, reviews have appeared covering the vast methodology developed to assemble these systems [5,6], but our focus here is only on recently reported one-flask, multistep processes. A review has recently been published on cascade reactions to prepare heterocycles [7], but it focused primarily on protocols to prepare indoles, with only minimal coverage of the derivatives described in this document.

Domino approaches to the construction of the title compounds can be broadly classified into five different categories: (1) reduction or oxidation followed by cyclization [8,9]; (2) $\mathrm{S}_{\mathrm{N}} \mathrm{Ar}$-terminated sequences [10]; (3) acid-catalyzed ring closures or rearrangements [11,12]; (4) high temperature cyclizations [13-15]; or (5) metal-promoted processes [16-18]. These are only the major strategies that will be addressed. Several less thoroughly studied transformations are also included, and all of the methods will be discussed in terms of mechanism, scope, yields, simplicity and potential utility.

\section{Survey of New Methodology}

\subsection{1,2,3,4-Tetrahydroquinolines}

Tetrahydroquinolines have long been important synthetic targets for chemists due to their ubiquitous distribution in natural products and medicinal agents [1,5,19-22]. Because it is an important structural motif in a large number of biologically active compounds, many synthetic schemes have been developed to prepare them. Domino reactions have proven to be particularly valuable for generating tetrahydroquinolines bearing previously inaccessible substitution patterns, and thus, many new drugs have been designed around these systems over the past two decades $[5,6]$.

Figure 1. Natural products incorporating tetrahydroquinolines.
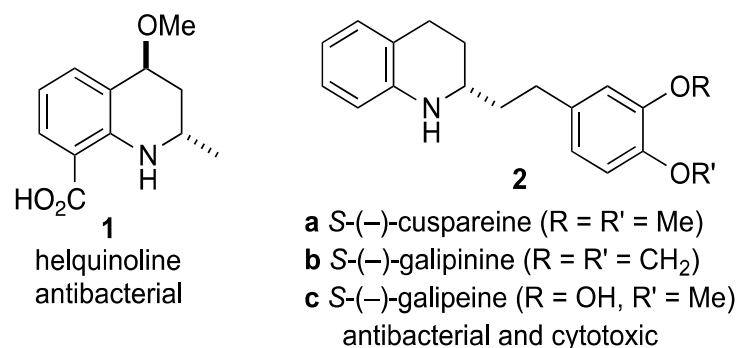

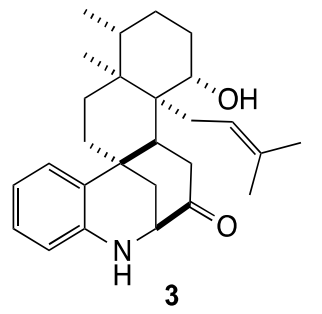

(+)-aspernomine cytotoxic
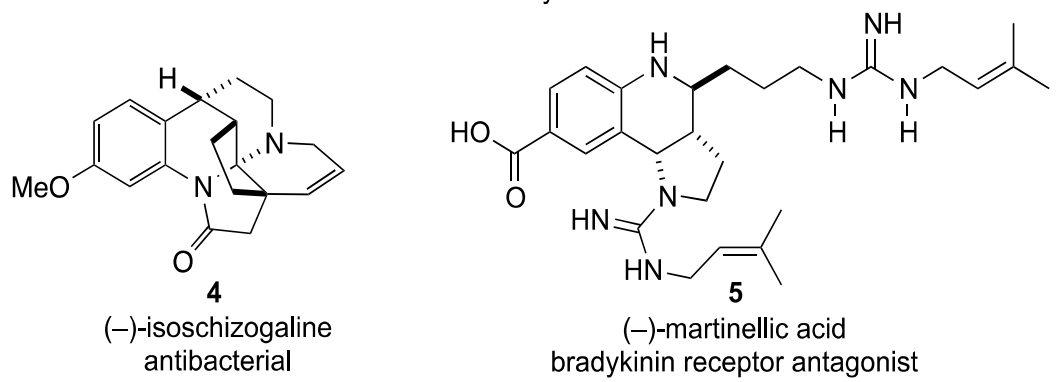
Tetrahydroquinolines embedded in natural product structures range from simple to complex. For example, helquinoline (1) is a relatively simple molecule with significant antibiotic properties [23]. Similarly, cuspareine (2a) and related compounds $\mathbf{2 b}$ and $\mathbf{2 c}$ have shown antibacterial as well as cytotoxic activity [24]. More complex systems include (+)-aspernomine (3), a potent cytotoxic agent [25] and $(-)$-isoschizogaline (4), a potentially useful antibiotic [26]. Finally, (-)-martinellic acid (5) is known to be a non-peptide antagonist for the bradykinin $\mathrm{B}_{1}$ and $\mathrm{B}_{2}$ receptors [27] (Figure 1).

The 1,2,3,4-tetrahydroquinoline nucleus is a prevalent core structure in a myriad of synthetic pharmaceuticals as well. Nicainoprol (6) is an antiarrhythmic drug [28], oxamniquine (7) is a schistosomicide [29], and virantmycin (8) is an antiviral antibiotic that also possesses antifungal activity [30-33]. Additionally, compound 9 is being evaluated for use in the treatment of HIV [34], compound $\mathbf{1 0}$ is garnering attention as an agent to slow the onset of Alzheimer's disease [35-37], and compound $\mathbf{1 1}$ is currently undergoing testing as an antimalarial agent [38]. Furthermore, compound 12 has demonstrated activity as a cholesterol ester transfer protein (CETP) inhibitor and may prove useful for ameliorating hypercholesterolipidemia [39,40], while L-689,560 (13) is a neuroprotective agent with potential to minimize ischemic nerve damage following a stroke or heart attack [41] (Figure 2).

Figure 2. Drugs incorporating tetrahydroquinolines.

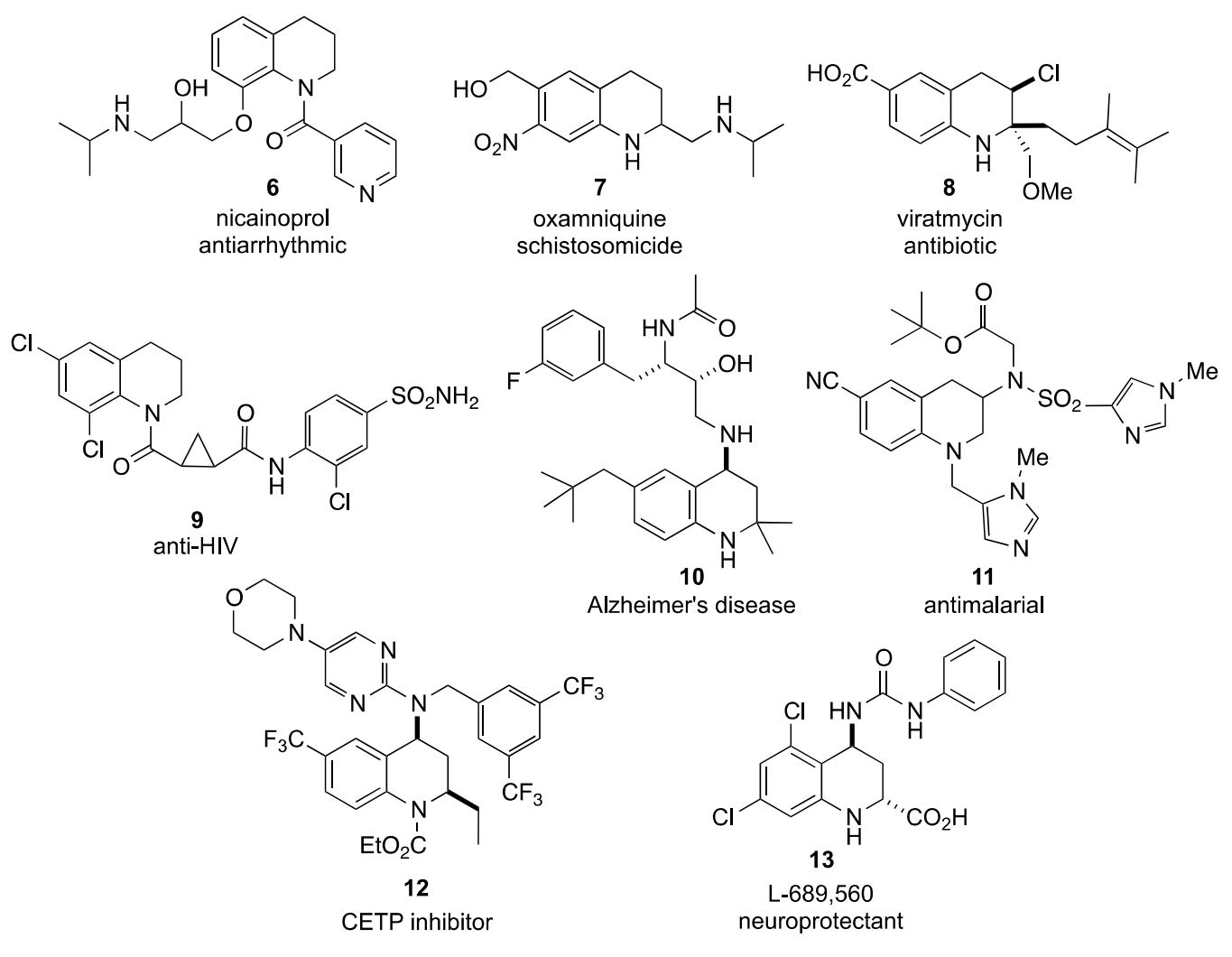

Beyond the structures depicted above, additional drug candidates incorporating tetrahydroquinolines have included analgesics [42], anticonvulsants [43], antidepressants [44-46], antipsychotics [47], antihypertensives [48-51], antiarrhythmics [52], antiallergenics [53], antimalarials [54], antitumor [55], anticancer [56], antifungal [57], antichagasic [58], and antiosteoporotics [59]. Other derivatives have exhibited significant immunosuppressant properties sparking studies of their potential as anti-rejection drugs $[60,61]$ and their inhibitory activity toward AMP activated protein kinase has attracted clinical 
interest as possible treatments for diabetes [62]. With such a wealth of pharmaceutical potential, it is no wonder that tetrahydroquinolines have been frequent targets for new synthetic methods.

Over the past decade, Bunce and co-workers have introduced several practical and efficient domino reactions to generate tetrahydroquinolines. One of these reported the conversion of 2-nitroarylketones and aldehydes to the target heterocycles using a reduction-reductive amination strategy under hydrogenation conditions with $5 \% \mathrm{Pd} / \mathrm{C}$ as catalyst [8]. This synthesis (Scheme 1) featured a multi-step sequence triggered by catalytic reduction of the nitro group in 14, followed by formation of cyclic imine 15, and further reduction to yield the tetrahydroquinolines 16 in $93 \%-98 \%$ yield. Reduction of the penultimate imine 15 was highly diastereoselective, giving hydrogen addition to the molecular face opposite the $\mathrm{C} 4$ ester group, resulting in a cis relationship between the $\mathrm{C} 2$ alkyl and $\mathrm{C} 4$ ester in 16. The authors further observed that addition of formaldehyde to the hydrogenation mixture resulted in the isolation of $\mathrm{N}$-methyltetrahydroquinoline derivatives [8]. Building on this strategy, these researchers also developed a reduction-double reductive amination sequence to convert $\mathbf{1 7}$ via $\mathbf{1 8}$ to the angular-fused tricyclic structures 19 with similar high diastereoselection in $60 \%-65 \%$ yield. One noteworthy finding from the reduction-double reductive amination study was that the process required a relatively large amount of catalyst $(>20 \mathrm{wt} \%)$, presumably due to poisoning of the catalyst after the initial cyclization.

Scheme 1. A domino reduction-reductive amination sequence.

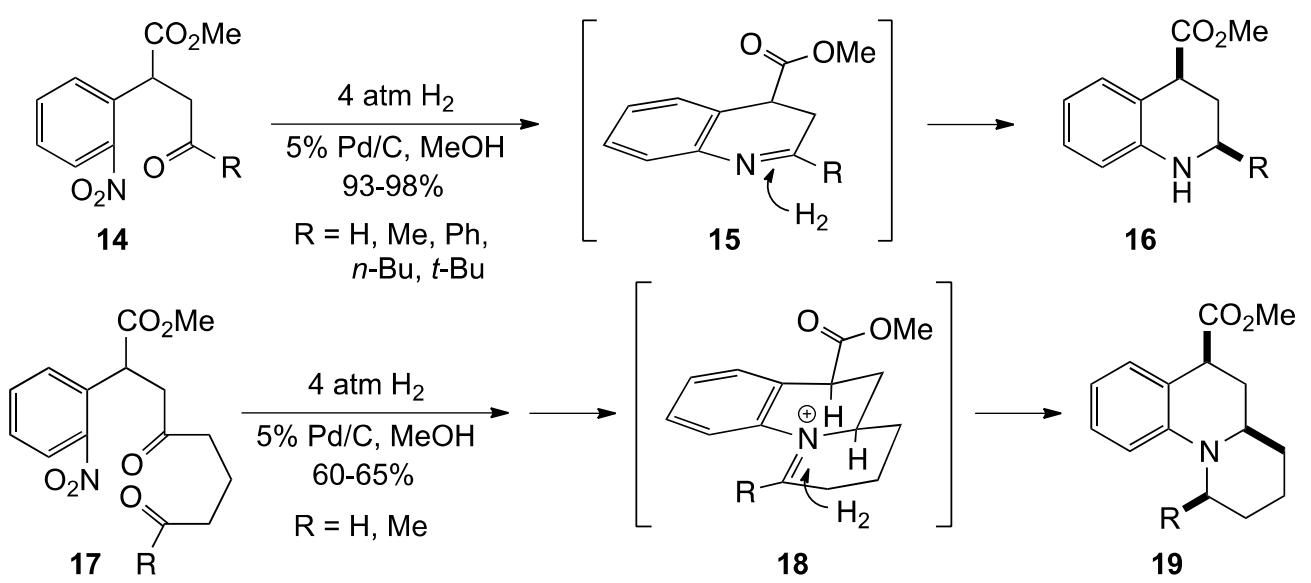

This same strategy was applied to the ring closure of $\mathbf{2 0}$ to give the angular 6-6-5 tricyclic ring structures 21 [63] (Scheme 2). This reaction exhibited the same high diastereoselectivity leading to the all-cis product. Unlike the less strained system above, however, this cyclization was found to be pressure dependent, with lower pressures of hydrogen (1-2 atm) giving by-products resulting from incomplete cyclization and higher pressures ( $5 \mathrm{~atm}$ ) affording the desired targets in $64 \%-66 \%$ yield.

Scheme 2. Strained angular fused systems by reduction-double reductive amination.

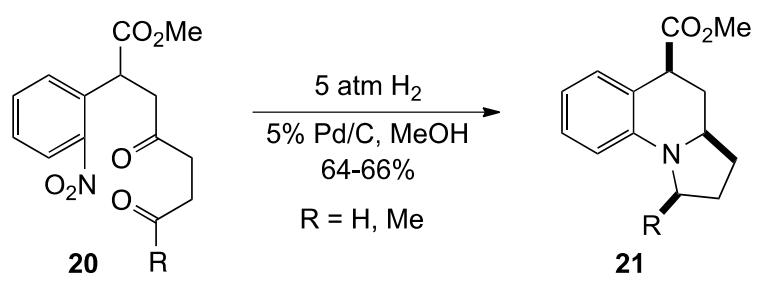


Encouraged by this initial success, the Bunce group pursued a similar ring closure to form linear tricyclic systems [64]. Substrates 22 were prepared in one-step and subjected to reductive cyclization using hydrogen and 5\% $\mathrm{Pd} / \mathrm{C}$ to give tetrahydroquinolines 23 in high yield (78\%-91\%) and with excellent selectivity ( $>98 \%$ ) for the trans-fused products (Scheme 3). Thus, as observed in the previous cyclizations, the bridgehead ester sterically directed the addition of hydrogen to the opposite face of the molecule resulting in a trans ring junction. Repeating these ring closures with substrates lacking the ester function led to mixtures of cis-and trans-fused products with a slight preference for the $c i s$.

Scheme 3. Linear fused systems by reduction-double reductive amination.
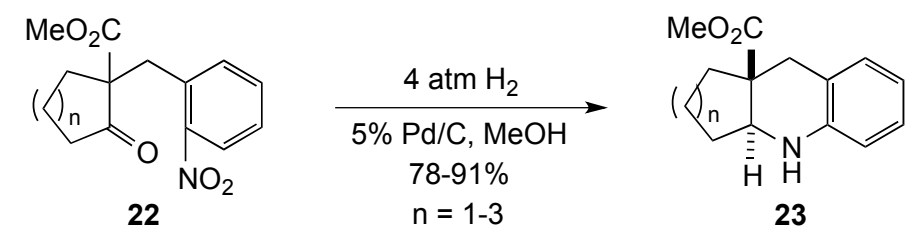

Additional understanding of the stereoselectivity in these ring closures was sought by moving the ester from the $\alpha$ to the $\beta$ carbon relative to the aromatic ring and introducing a sterically demanding methyl substitutent geminal to the ester [65]. A two-step synthesis furnished precursors 24, which on reductive cyclization, produced 26 and 27, respectively, in 78\%-87\% yield (Scheme 4). While the product having the $\mathrm{C} 2$ alkyl cis to the $\mathrm{C} 3$ ester still predominated in ratios of $6: 1$ to $16: 1$, the greater conformational flexibility about the $\beta$ carbon in these substrates diminished the absolute cis selectivity observed in substrates bearing the ester group $\alpha$ to the aromatic ring. An apparent conformational preference for a pseudoaxial ester in 25a was invoked to rationalize the bias toward the cis product in this reaction.

Scheme 4. A reduction-reductive amination sequence.
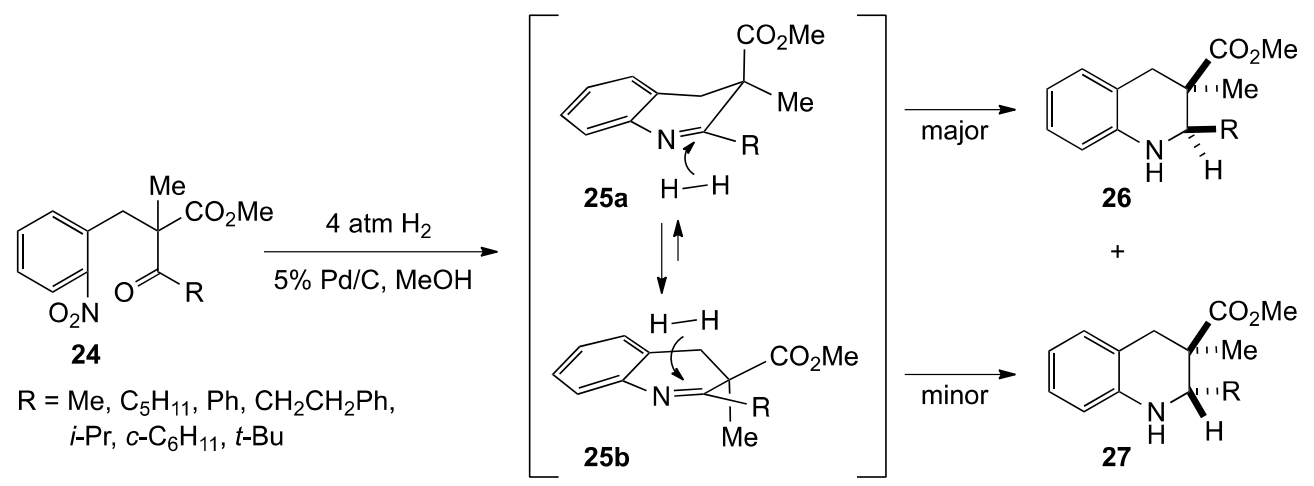

A subsequent study examined ring closures in related substrates $\mathbf{2 8}$, bearing an ester at the $\beta$ carbon with the geminal methyl replaced by hydrogen [66]. Interestingly, this reaction proved to be highly catalyst dependent. Hydrogenation of 28 at 1 atm using $5 \% \mathrm{Pd} / \mathrm{C}$ afforded primarily dihydroquinoline 29, while at 4 atm, quinoline 30 was the major product. By changing the catalyst to $5 \% \mathrm{Pt} / \mathrm{C}$ (4 atm $\mathrm{H}_{2}$ ), however, the double bond migration and aromatization pathways were dramatically reduced, and formation of tetrahydroquinoline $\mathbf{3 1}$ dominated with the cis isomer favored by $\geq 13: 1$ over the trans. Contrary to expectation, larger $\mathrm{R}$ groups gave higher cis selectivity for the substituents in the isolated heterocycles. To rationalize this observation, a steric interaction between $\mathrm{R}$ and the ester was assumed 
in the intermediate imine. This would oblige the ester to adopt a pseudoaxial orientation, as in 32, which would direct hydrogen addition from the distal face of the molecule to generate the cis product (Scheme 5). These results demonstrated the importance of catalyst and steric shielding on the reaction outcome.

Scheme 5. Catalyst and steric shielding effects in the reduction-reductive amination.

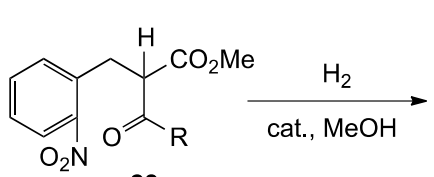

28

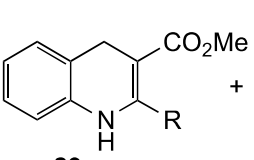

29

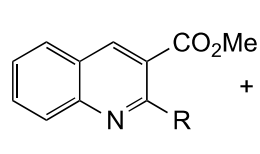

30

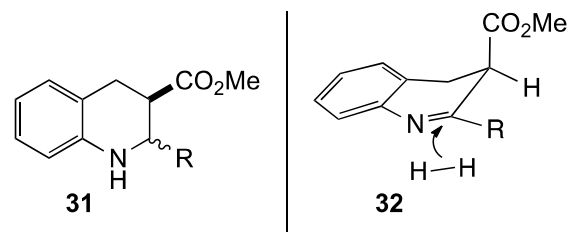

$\mathrm{R}=\mathrm{Me}, \mathrm{C}_{5} \mathrm{H}_{11}, \mathrm{Ph}, \mathrm{CH}_{2} \mathrm{CH}_{2} \mathrm{Ph}, i-\mathrm{Pr}, c-\mathrm{C}_{6} \mathrm{H}_{11}, t-\mathrm{Bu}$

Domino processes initiated by dissolving metal reductions were also investigated as a strategy for synthesizing tetrahydroquinolines [67]. Substrates 33 underwent reduction with iron powder in acetic acid to yield anilines 34, which were captured in a favorable 6-exo-trig Michael addition with the side chain acrylate moiety to afford 35 in $86 \%-98 \%$ yield (Scheme 6 ). The geometry of the double bond and hindrance at the Michael terminus had a minimal impact on the cyclization process.

Scheme 6. A reduction-Michael addition sequence.

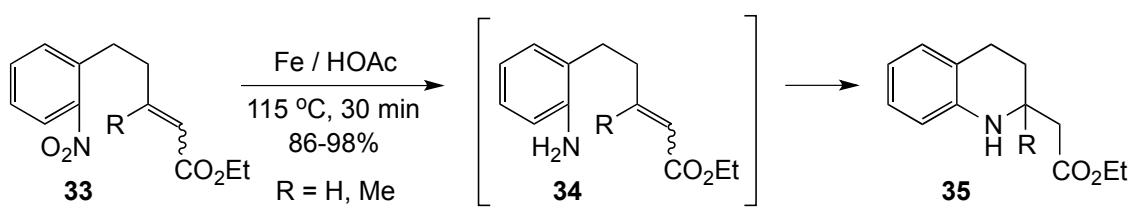

In an extension of this study, divergent reactivity was observed for the reduction-Michael reaction involving 4-(2-nitrobenzyl)-2-cycloalken-1-one systems 36 [68]. In this project, two substrates, differing only in the Michael acceptor ring size, were prepared and reacted with iron in acetic acid. Reduction of the nitro group, followed by conjugate addition of the resulting aniline to the enone moiety, proceeded predictably for the cyclopentenone precursor to give the linear tricyclic system $\mathbf{3 7}$ in $76 \%$ yield. Somewhat surprisingly, the bridgehead ester of the expected product was also reduced during this reaction. The cyclohexenone substrate, on the other hand, produced the spirocyclic amide 38 as the only product in $95 \%$ yield. These results were attributed to the difference in strain as well as alignment of the reacting centers in the two systems. It was reasoned that the more reactive five-membered ring would adopt conformation 39, which positions the aniline nitrogen to add to the enone double bond. The six-membered ring, on the other hand, would assume conformation $40 \mathrm{~b}$ to avoid steric interaction of the amino function with the $\mathrm{C} 5$ ring carbon (viz. 40a) resulting in preferential closure on the ester group to give the amide (Scheme 7).

Scheme 7. Divergent reactivity based on ring size.
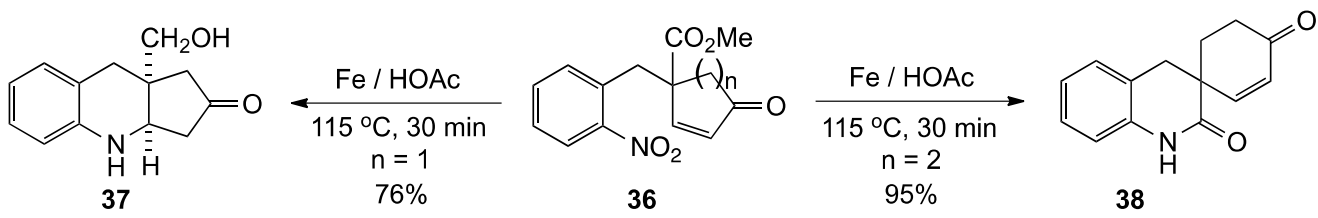

36

38 
Scheme 7. Cont.
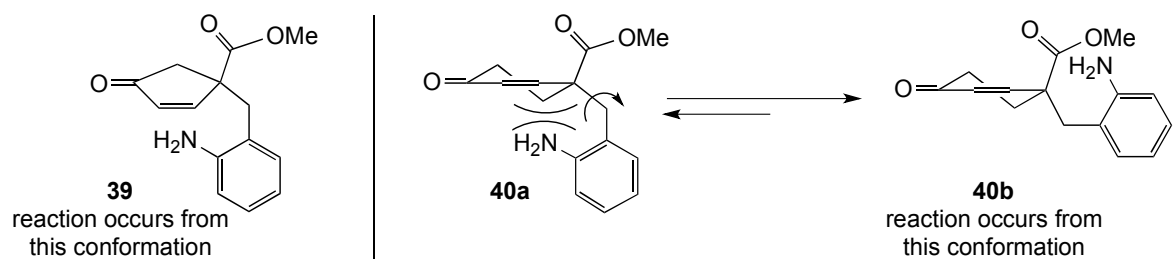

In a subsequent investigation, Bunce and co-workers designed a system to gauge the feasibility of a domino reductive amination-nucleophilic aromatic substitution $\left(\mathrm{S}_{\mathrm{N}} \mathrm{Ar}\right)$ sequence for the preparation of tetrahydroquinolines $[69,70]$. From a mechanistic standpoint, it was anticipated that an initial reductive amination to the side chain carbonyl group would yield an amine, which would undergo $\mathrm{S}_{\mathrm{N}} \mathrm{Ar}$ ring closure with the activated aromatic acceptor. In practice, the reaction proved highly successful and produced the desired heterocycles in 58\%-98\% yields. Ketones (e.g., 41, $\mathrm{R}^{1}=\mathrm{Me}$ ) furnished superior yields in comparison to aldehydes $\left(\mathrm{R}^{1}=\mathrm{H}\right)$ due to their increased stability toward the reaction conditions and because of steric interactions in a proposed chair-like conformation for ring closure. According to this hypothesis, the $\alpha$ methyl group in amine $42\left(\mathrm{R}^{1}=\mathrm{Me} ; \mathrm{R}^{2}=\right.$ alkyl), produced from 41, should adopt a pseudoequatorial orientiation, which would juxtapose the reactive sites and promote the ring closure to $\mathbf{4 3}$ (Scheme 8). On the other hand, an aldehyde-derived amine would be expected to exhibit a more random conformation that would make the cyclization less favorable. The limitation of this process is associated with the $\mathrm{S}_{\mathrm{N}} \mathrm{Ar}$ ring closure, as it will proceed only if there is an electron-withdrawing group, such as $\mathrm{NO}_{2}$, at $\mathrm{C} 4$ (or $\mathrm{C} 2$ ) relative to the fluorine.

Scheme 8. A reductive amination- $\mathrm{S}_{\mathrm{N}} \mathrm{Ar}$ reaction.

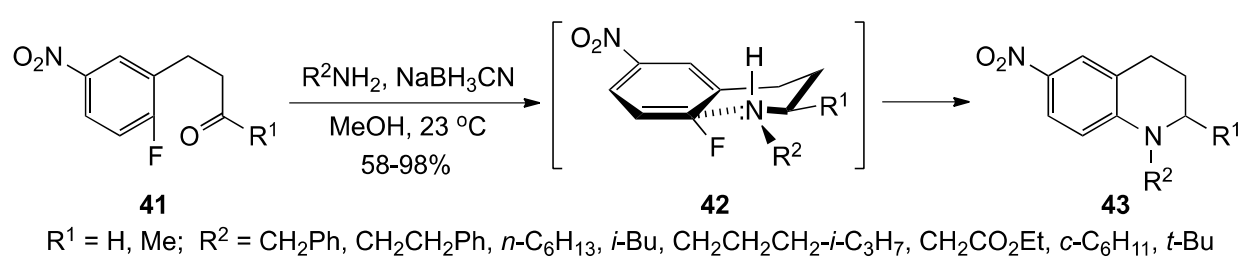

Bunce and co-workers continued to exploit the $\mathrm{S}_{\mathrm{N}} \mathrm{Ar}$ terminating event in a domino $\mathrm{S}_{\mathrm{N}} 2-\mathrm{S}_{\mathrm{N}} \mathrm{Ar}$ tetrahydroquinoline synthesis [10,71]. Specifically, this process involved an intermolecular $\mathrm{S}_{\mathrm{N}} 2$ reaction of benzylamine with the primary side chain bromide in $\mathbf{4 4}$, followed by an intramolecular $\mathrm{S}_{\mathrm{N}} \mathrm{Ar}$ displacement of fluoride from the activated aromatic ring. The reaction proceeded in DMF at ambient temperature to afford a 98\% yield of $\mathbf{4 5}$ (Scheme 9). Unfortunately, only one case of this transformation was reported, and thus, the full potential of the process has not been established.

Scheme 9. An $\mathrm{S}_{\mathrm{N}} 2-\mathrm{S}_{\mathrm{N}} \mathrm{Ar}$ reaction
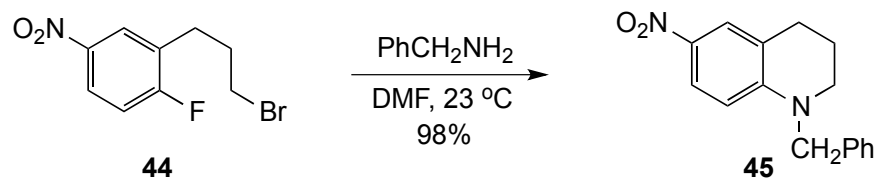

Assembly of tetrahydroquinolines by consecutive additions to a 4-nitrofluorobenzene and a Michael acceptor in $\mathbf{4 6}$ to give 47, was also investigated by the Bunce group [71] (Scheme 10). The reaction 
gave $82 \%-97 \%$ yields for unhindered amines but was sensitive to steric bulk $\alpha$ to the amine nitrogen. Heterocyclization could conceivably occur by an $\mathrm{S}_{\mathrm{N}} \mathrm{Ar}$ addition to the 1-fluoro-4-nitrobenzene, followed by Michael reaction with the side chain acrylate or by the reverse sequence. The reaction chronology was inferred by competitive reaction of benzylamine with separate mixtures of 2-fluoro-5nitrotoluene with methyl $(E)$-5-phenyl-2-pentenoate and $(E)$-1,5-diphenyl-2-penten-1-one at $50{ }^{\circ} \mathrm{C}$. For the unsaturated ester, preferential reaction occurred with the nitroarene suggesting an $\mathrm{S}_{\mathrm{N}} \mathrm{Ar}$-Michael sequence, while the ketone (a better Michael acceptor) was less conclusive, showing only a slight preference for the $\mathrm{S}_{\mathrm{N}} \mathrm{Ar}$ reaction.

Scheme 10. An $\mathrm{S}_{\mathrm{N}} \mathrm{Ar}-\mathrm{Michael}$ sequence.
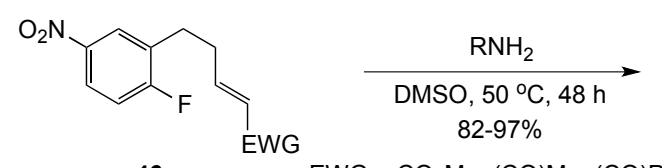

$\mathrm{EWG}=\mathrm{CO}_{2} \mathrm{Me},(\mathrm{CO}) \mathrm{Me},(\mathrm{CO}) \mathrm{Ph}$ $\mathrm{R}=\mathrm{CH}_{2} \mathrm{Ph}, \mathrm{CH}_{2} \mathrm{CH}_{2} \mathrm{Ph}, n-\mathrm{C}_{6} \mathrm{CH}_{13}$,

$i$-Bu, $c-\mathrm{C}_{6} \mathrm{H}_{11}$

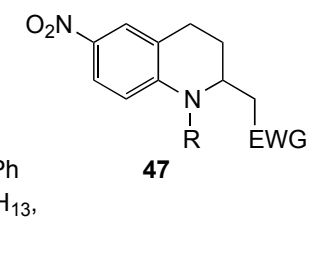

In 2002, the Fujita group unveiled a new metal-catalyzed oxidative cyclization of amino alcohols 48 to tetrahydroquinolines $\mathbf{4 9}$ in the presence of dichloro(pentamethylcyclopentadienyl)iridium(III) dimer and base [9]. Although the mechanism was unclear, it was postulated that the iridium complex acted on 47 to catalytically oxidize the alcohol to aldehyde 50. This aldehyde was then captured by the proximal amino group to form imine 51, which was reduced to the tetrahydroquinoline 49 by the hydrido iridium species produced during the oxidation (Scheme 11). This reaction was also extended to structures bearing a two-carbon side chain, where an alternative mechanistic scenario was proposed to give indoles.

Scheme 11. A metal-catalyzed oxidative cyclization of amino alcohols.
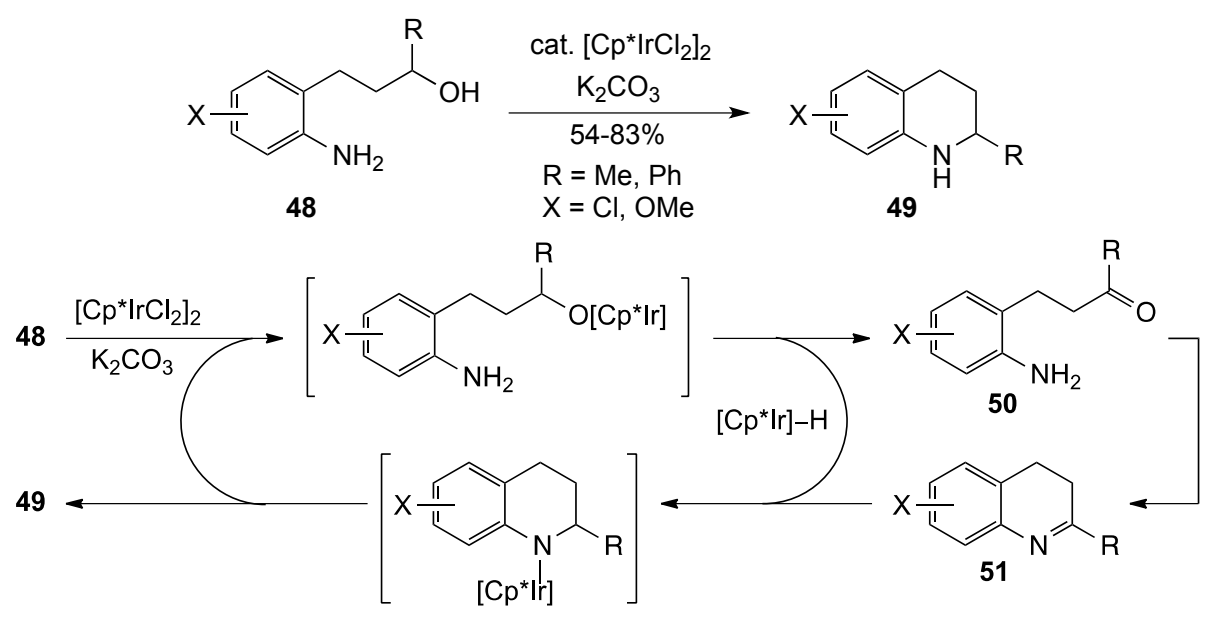

In 2010, Patti and Pedotti published a simple method for converting 2-nitrochalcones 52 to tetrahydroquinolines 53 via a reductive cyclization under catalytic hydrogenation conditions [72] (Scheme 12). Rapid reduction of the side chain double bond, in addition to the nitro group, was essential to prevent the formation of quinoline by-products. The solvent reportedly played a crucial role in this hydrogenation process, with dichloromethane affording the best selectivity and highest 
yields (65\%-90\%). Operational simplicity, excellent atom economy, and low $\mathrm{H}_{2}$ pressures were advantages of this process, but the required use $10 \mathrm{wt} \%$ of $10 \% \mathrm{Pd} / \mathrm{C}$ was a drawback.

Scheme 12. Reductive cyclization of 2-nitrochalcones.

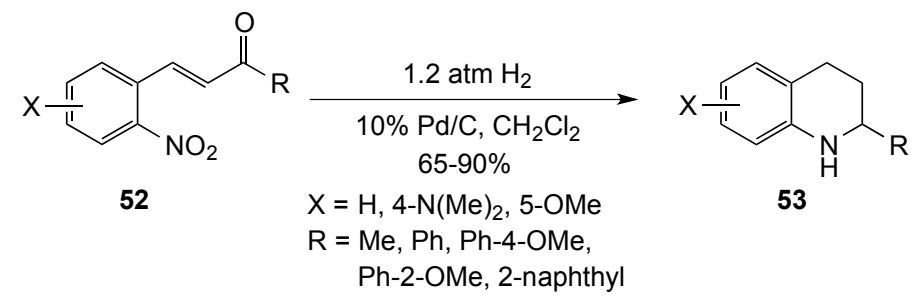

Che and co-workers recently disclosed a metal-mediated heterocyclization of $\mathbf{5 4}$ to $\mathbf{5 5}$ involving an intramolecular nitrene $\mathrm{C}-\mathrm{H}$ insertion process promoted by the commercially available, air-stable [Fe(III)( $\left.\left.\mathrm{F}_{20} \mathrm{TPP}\right) \mathrm{Cl}\right]$ complex [ $\mathrm{F}_{20} \mathrm{TPP}=$ meso-tetrakis(pentafluorophenyl)porphyrinato dianion] [73]. The process offered a one-step route to a limited selection of 2-aryl-1,2,3,4-tetrahydroquinolines in $72 \%-81 \%$ yields. The proposed mechanism involved sequential formation of iron-nitrene complex 56, abstraction a side chain $\gamma$-hydrogen to give benzylic radical 57, and cyclization to product $\mathbf{5 5}$ (Scheme 13).

Scheme 13. A metal-mediated heterocyclization of aryl azides.

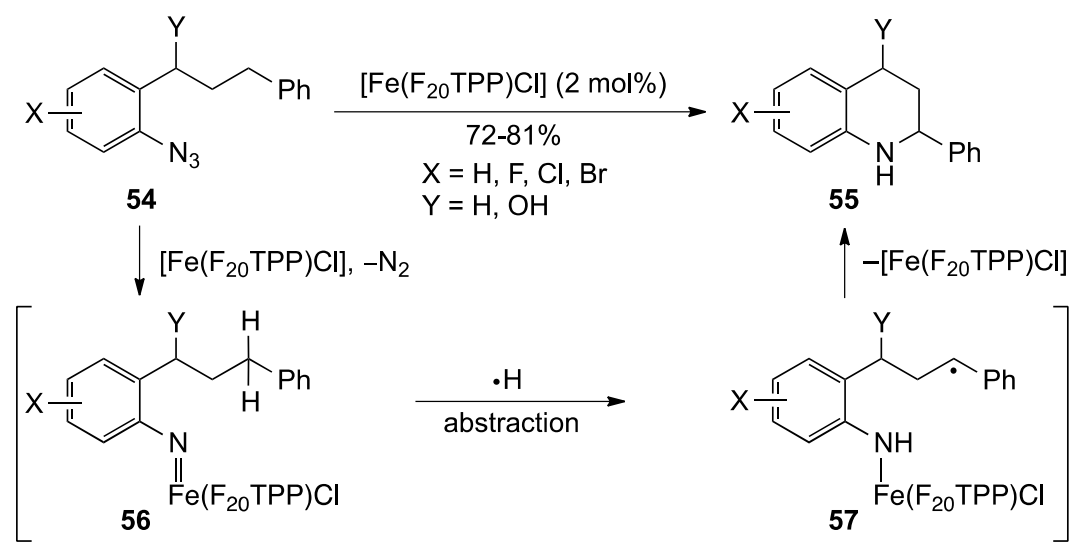

Söderberg et al. have applied a novel thermal annulation reaction of $\mathrm{N}$-(2-alkenylphenyl)aminosubstituted chromium Fischer carbenes 58 to synthesize tetrahydroquinolines 59 [74] (Scheme 14). The extent of product formation was found to be dependent on the solvent as well as steric and electronic factors in the substrates. Yields were highest when acetonitrile was the solvent, but the results were highly variable $(12 \%-70 \%)$ and no preferred substitution pattern favoring heterocycle formation emerged from the study. The major by-products were quinoline and 2-aminostyrene.

Scheme 14. Thermal cyclizations of chromium Fischer carbenes.

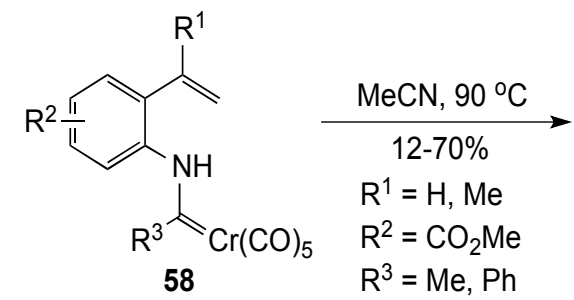<smiles>[R][M]1C=c2cc[Y1]cc2=C([R])CC([R])N1</smiles> 
Gigant and Gillaizeau reacted enamides 60 with benzyl azide 61 under acid conditions in a novel synthesis of fused-ring tetrahydroquinolines 62 [12]. In this scheme, treatment of the reactants with triflic acid spurred rearrangement of $\mathbf{6 1}$ to give an $N$-phenyliminium intermediate 63. Subsequent nucleophilic addition of $\mathbf{6 0}$ to this iminium species gave $\mathbf{6 4}$, which cyclized to the desired heterocycles 62 (Scheme 15). The sequence provided the products in $23 \%-85 \%$ yields with complete cis diastereoselectivity. The scope of the reaction was further expanded to include the use of 5,6-benzo-fused enamides, which produced tetracyclic products.

Scheme 15. Cyclization of enamides with benzyl azide.

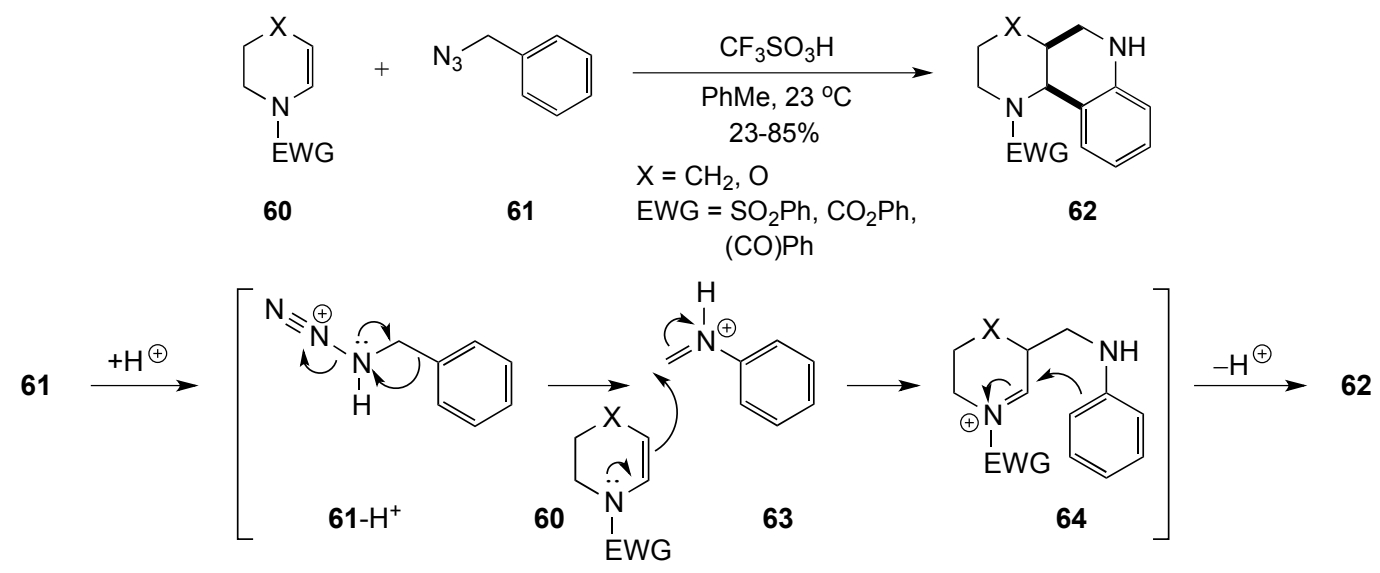

Ortiz-Marciales and co-workers have documented a simple protocol to convert 1 -indanone $O$-TBS oxime (65) to tetrahydroquinoline (67) using 2 eq. of borane-tetrahydrofuran complex [75]. A mechanism was not offered, but likely involved carbon-nitrogen double bond reduction in $\mathbf{6 5}$, followed by formal $\alpha$-elimination of $\mathrm{TBSOBH}_{2}$ with aryl migration to the electron-deficient nitrogen to generate the six-membered cyclic imine 66 (Scheme 16). Various borohydrides in the mixture would then reduce the imine double bond and yield the product. Unfortunately, this study reported only one example of this process leading to the unsubstituted derivative $\mathbf{6 7}$, and thus, the generality of the process is unclear.

Scheme 16. Tetrahydroquinoline from 1-indanone $O$-TBS oxime.

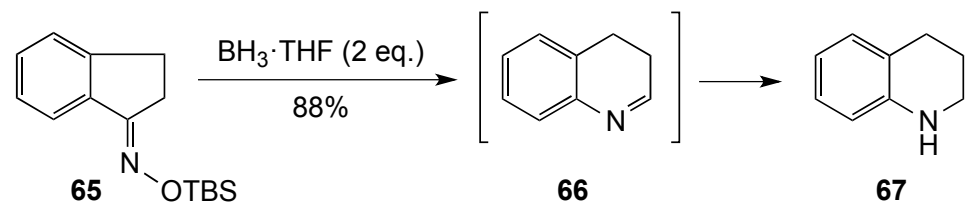

The Miyata group advanced a related option for the conversion of $N$-indanyl(methoxy)amines $\mathbf{6 8}$ to 2-substituted tetrahydroquinolines 69 by treatment of the former with 3 eq. of an organomagnesium or organolithium reagent [16]. The route involved a domino sequence initiated by deprotonation of the nitrogen and coordination of an organometallic species with oxygen to give 70. Rearrangement of the resulting arylmethylamide with loss of methoxide to generate the ring-expanded imide 71, and addition of a molecule of the organometallic reagent to the imide would then afford product 69 (Scheme 17). The reaction generally required electron-donating groups on the aromatic ring and achieved yields in 
the $33 \%-94 \%$ range. The lowest yields were observed when $\mathrm{R}^{3}$ was methyl or phenyl. The proposed mechanism for this rearrangement is formulated below.

Scheme 17. Tetrahydroquinolines from $N$-indanyl(methoxy)amines.

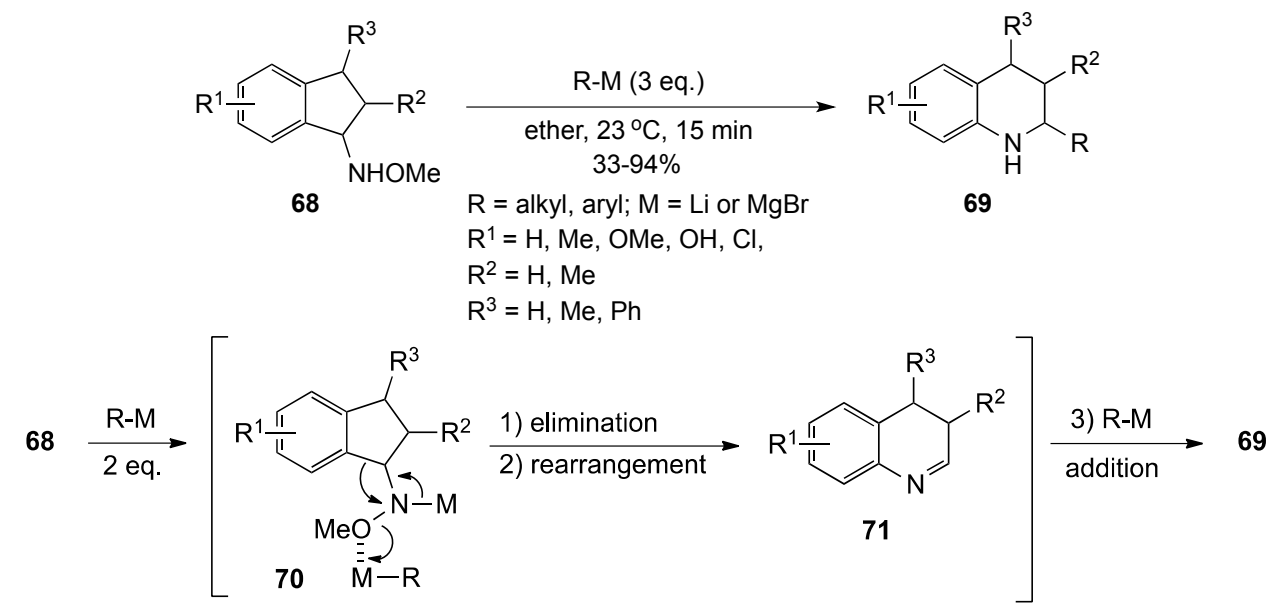

These same authors validated the utility of this reaction by exploiting it in a stereoselective formal synthesis of the alkaloid ( \pm )-martinellic acid (5). The key intermediate $\mathbf{7 3}$ was prepared from bromoacetal 72 in 9 steps (12\% yield, 34\% based on recovered starting material). Treatment of 73 with 3 eq. of allylmagnesium bromide in ether then gave $\mathbf{7 4}$ in $94 \%$ yield. This intermediate was subsequently elaborated in three steps (55\% yield) to relay structure $\mathbf{7 5}$, which had been previously converted to $( \pm)-5$ [27] (Scheme 18).

Scheme 18. Synthesis of $( \pm)$-martinellic acid.

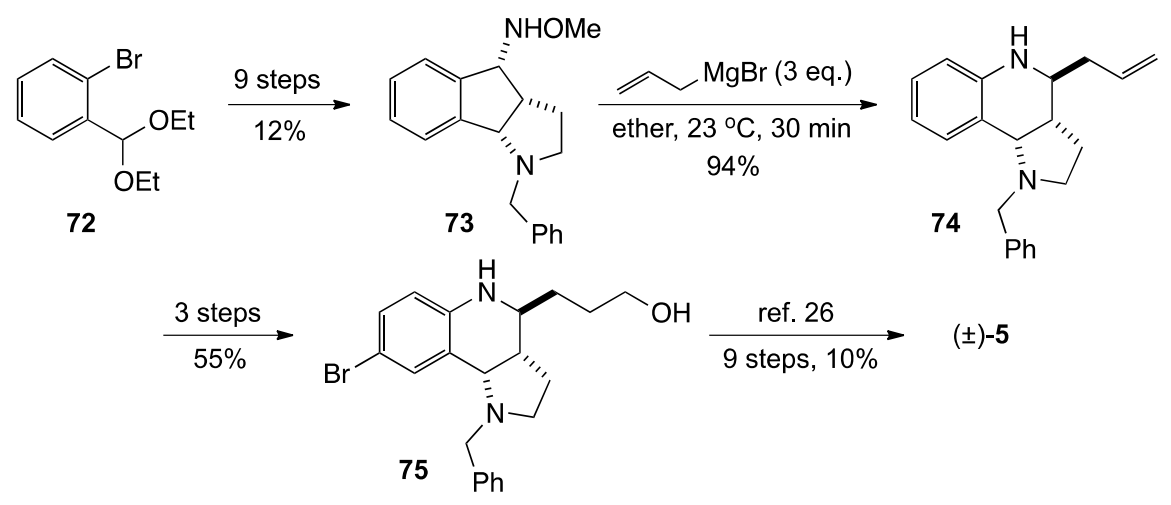

Finally, a photochemical approach to tetrahydroquinolines involving irradiation of an ethanol solution of 3-methyl-1-nitrobenzene (76) at $350 \mathrm{~nm}$ in the presence of $\mathrm{TiO}_{2}$ was reported by Park and co-workers [76]. Under these conditions, it was proposed that $\mathrm{TiO}_{2}$ catalyzed reduction of 76 to the aniline and simultaneous oxidation of ethanol to acetaldehyde. In ethanol solvent, some of the acetaldehyde likely existed as the diethyl acetal, which upon loss of ethanol, would give ethyl vinyl ether. Addition of this vinyl ether to the imine derived from 3-methylaniline and acetaldehyde, would then deliver 4-ethoxy-2,7-dimethyl-1,2,3,4-tetrahydroquinoline (77) (Scheme 19). Although the yield was respectable $(71 \%)$, the reaction scope was not addressed in this report, and thus, the generality of the process remains unknown. 
Scheme 19. A photochemical synthesis of tetrahydroquinolines.
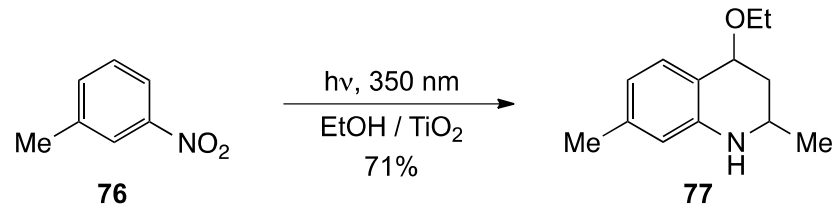

\subsection{2,3-Dihydro-4(1H)-quinolinones}

2,3-Dihydro-4(1H)-quinolinones can essentially be thought of as aza-analogs of flavanones. While many of these derivatives are intermediates in syntheses of 4(1H)-quinolinones [77], some express medicinal properties of their own [78]. Most drugs possessing this pharmacophore are simple 2-aryl-substituted derivatives such as 78 [79,80] and 79 [81] (Figure 3). Other dihydroquinolinones, with more diverse substitution, are under consideration as treatments for high blood pressure [82,83], pain [84] and Alzheimer's disease [85,86]. One patent also asserts that several members of this compound family are useful as pesticides [87].

Figure 3. Drugs incorporating 2,3-dihydro-4(1H)-quinolinones.

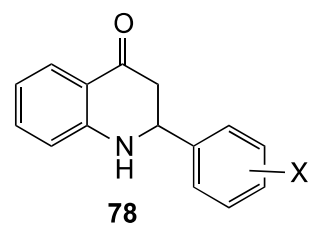

a $\mathrm{X}=2-\mathrm{OH}$ anti-ulcer

b $\mathrm{X}=4-\mathrm{Cl}$ antiinflammatory

c $\mathrm{X}=4-\mathrm{Br}$ anticancer

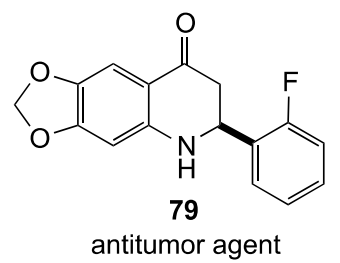

A concise and straightforward preparation for $N$-alkyl-2,3-dihydro-4(1H)-quinolinones has been pioneered by Bunce and co-workers using a domino Michael-S $\mathrm{S}_{\mathrm{N}} \mathrm{Ar}$ approach [88]. The requisite 1-aryl-2-propen-1-one derivatives 80, which incorporated both Michael and $\mathrm{S}_{\mathrm{N}} \mathrm{Ar}$ acceptors, were efficiently accessed in two steps. Treatment of these substrates with a selection of primary amines afforded the dihydroquinolinones $\mathbf{8 1}$ in $54 \%-78 \%$ yield by Michael addition to the enone, followed by $\mathrm{S}_{\mathrm{N}} \mathrm{Ar}$ ring closure (Scheme 20). One drawback to the method was that the final ring closure did not tolerate the presence of electron-donating groups on the $\mathrm{S}_{\mathrm{N}} \mathrm{Ar}$ acceptor ring. Additionally, though nitro activation was not essential to the process, yields were diminished in less activated systems when the incoming amine was branched $\alpha$ to the nitrogen.

Scheme 20. A domino Michael-S $\mathrm{N}_{\mathrm{N}} \mathrm{Ar}$ approach.<smiles>[X]c1ccc(F)c(C(=O)C=C)c1</smiles>

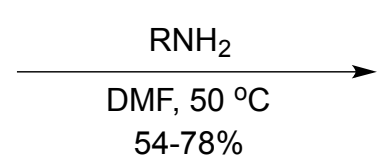<smiles>[X]c1ccc2c(c1)C(=O)CCN2[R]</smiles>

80

$$
\begin{aligned}
\mathrm{X}= & \mathrm{H}, \mathrm{NO}_{2} \\
\mathrm{R}= & \mathrm{CH}_{2} \mathrm{Ph}, \mathrm{CH}_{2} \mathrm{CH}_{2} \mathrm{Ph}, n-\mathrm{C}_{6} \mathrm{H}_{13}, \\
& \mathrm{CH}_{2} \mathrm{CH}_{2} \mathrm{CH}_{2} \mathrm{O}-i-\mathrm{Pr}, i-\mathrm{Bu}, \\
& c-\mathrm{C}_{6} \mathrm{H}_{11}, t-\mathrm{Bu}, \mathrm{Ph}
\end{aligned}
$$


Bunce and Schammerhorn have described a new domino strategy for the synthesis of highly substituted 2,3-dihydro-4(1H)-quinolinones using an imine addition-S $\mathrm{S}_{\mathrm{N}} \mathrm{Ar}$ approach [89]. Reaction of tert-butyl 2-fluoro-5-nitrobenzoylacetate (82) with pre-formed imines $\mathbf{8 3}$ at room temperature furnished the target compounds $\mathbf{8 4}$ in a single operation. The annulations were successful with aldimines, but failed to yield the desired targets using more sterically demanding ketimines. The sequence proceeded by addition of ketoester 82 to imine 83, followed by $\mathrm{S}_{\mathrm{N}} \mathrm{Ar}$ reaction of the resulting secondary amine to furnish the dihydroquinolinones as the stable enols 84 in $74 \%-97 \%$ yields (Scheme 21). Base was not required for the reaction to occur. Precursors with methyl and ethyl esters gave comparable results, but tert-butyl esters were deemed more versatile for subsequent transformations.

Scheme 21. An imine addition- $\mathrm{S}_{\mathrm{N}} \mathrm{Ar}$ sequence.

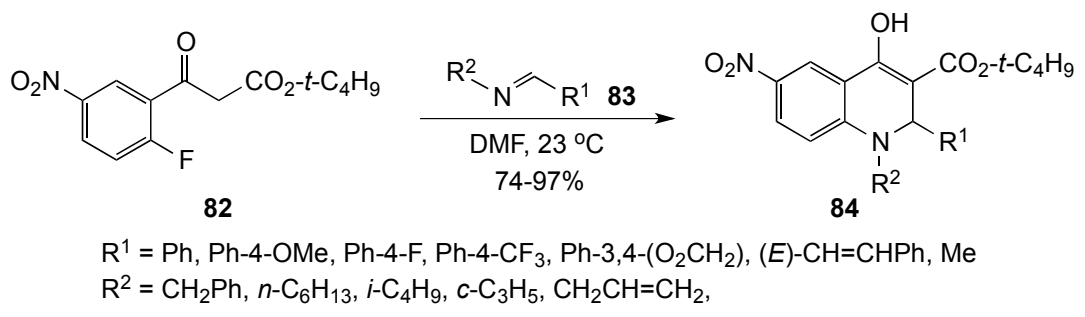

A Fries-like rearrangement of $\mathrm{N}$-arylazetidin-2-ones $\mathbf{8 5}$ promoted by triflic acid formed the basis of a synthesis of 2,3-dihydro-4(1H)-quinolinones $\mathbf{8 6}$ reported by Banwell and co-workers [11] (Scheme 22). This procedure is a modification of an earlier report by Kano et al. [90], which utilized refluxing trifluoroacetic acid as the solvent/catalyst. The use of triflic acid, however, permitted reactions at room temperature with greater product returns. Yields were generally in the 30\%-96\% range, but lower when electron-withdrawing substituents were positioned on the aromatic ring. Two earlier papers by Anderson and Tepe reported this same reaction in 1,2-dichloroethane with fewer examples but similar results [91,92]. A disadvantage of these recent studies was the high cost of the azetidin-2-one used to synthesize the substrates. The initial report by Kano [90] and one by Gomtsyan [93] gave more economical preparations.

Scheme 22. A Fries-like rearrangement of $N$-arylazetidin-2-ones.

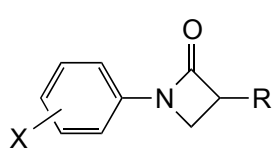

85

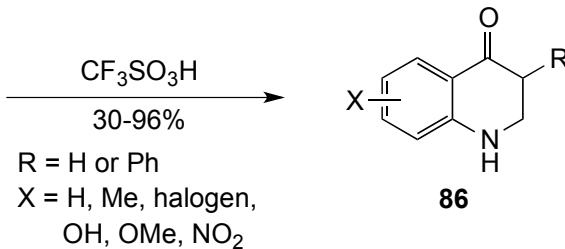

A protocol to access 2-aryl-2,3-dihydro-4(1H)-quinolinones in $72 \%-88 \%$ yield via a dissolving metal reduction-cyclization sequence has also appeared [94]. The domino sequence was initiated by reduction of the nitro group of $\mathbf{8 7}$ using iron powder in acids of varying strength. A series of experiments revealed that iron in concentrated $\mathrm{HCl}$ at $100{ }^{\circ} \mathrm{C}$ for $30 \mathrm{~min}$ afforded superior results, suggesting that strong acid is the key to efficient conversions. Following reduction of the nitro group, 
cyclization to $\mathbf{8 8}$ presumably involved addition of the aniline amino group to the protonated enone (Scheme 23).

Scheme 23. A dissolving metal reduction-cyclization reaction.
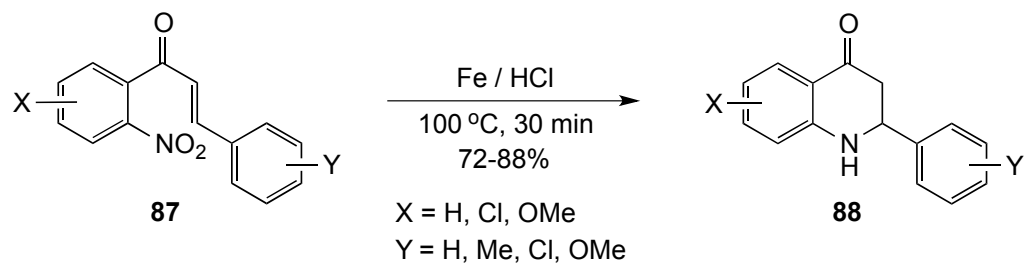

The Chandrasekar group explored a possible asymmetric route to 2-aryldihydroquinolinones from 2-aminoacetophenone (89) and benzaldehydes 90 using L-proline as a catalyst at room temperature [95]. Although the desired products 91 were isolated in 79\%-93\% yields, the observed ees were $<10 \%$. An advantage of this method was that the reaction proceeded with both electron-donating and electron-withdrawing X groups on the aldehyde reacting partner (Scheme 24).

Scheme 24. A proline-catalyzed cyclization of 2-aminoactophenone and benzaldehydes.<smiles>CC(=O)c1ccccc1N</smiles>

89<smiles>[X]c1ccc(C=O)cc1</smiles>

90

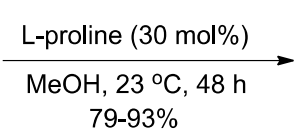
$\mathrm{X}=\mathrm{H}, \mathrm{Me}, \mathrm{OMe}$

$\mathrm{Cl}, \mathrm{F}, \mathrm{CF}_{3}$

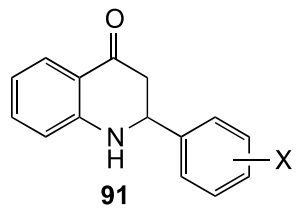

91

The Nepali group offered an alternative synthesis of similar structures from acetamidochalcones 92 [77]. The reactions proceeded by sequential hydrolysis of the amide, followed by Michael addition to the unsaturated ketone to give the 2,3-dihydroquinolinones 93 (Scheme 25). Although 15 cases were reported, only one yield of 56\% was recorded for $93(\mathrm{X}=\mathrm{H})$ since the intended aim of this study was the synthesis of the corresponding $4(1 H)$-quinolinones. The ring closure likely proceeded as described for the previous reaction.

Scheme 25. Domino hydrolysis-cyclization of acetamidochalcones.

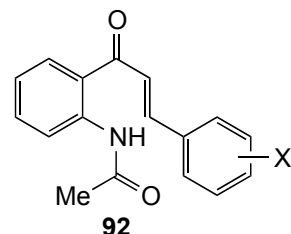

92

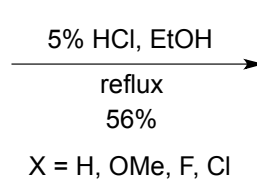

$\mathrm{X}=\mathrm{H}, \mathrm{OMe}, \mathrm{F}, \mathrm{Cl}$

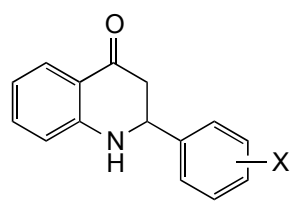

93

Hamada and co-workers have described an interesting multi-catalytic approach to 3-substituted 2,3-dihydro-4(1H)-quinolinones [96]. This process involves sequential Pd-catalyzed $\mathrm{N}$-alkylation of 2-methanesufonamidobenzaldehydes 94 with allylic acetates 95 to give aldehyde 96, followed by intramolecular thiazolium salt-catalyzed Stetter reaction between the aldehyde in $\mathbf{9 6}$ and the side chain Michael acceptor to generate heterocycle 97. The Stetter reaction is a variant of the well-known thiazolium-catalyzed benzoin condensation, where the intermediate anion 99 is captured by 1,4-addition to an unsaturated system rather than 1,2-addition to a carbonyl. The mechanism, applied to the conversion of 
96 to 97, is outlined below (Scheme 26). The one-flask domino version of the reaction was examined for a small selection of compounds, but the results were erratic, with several reactions giving near quantitative yields and others failing completely. Thus, further work is necessary to fully elucidate and optimize this process.

Scheme 26. A multi-catalytic approach to 2,3-dihydro-4(1H)-quinolinones.

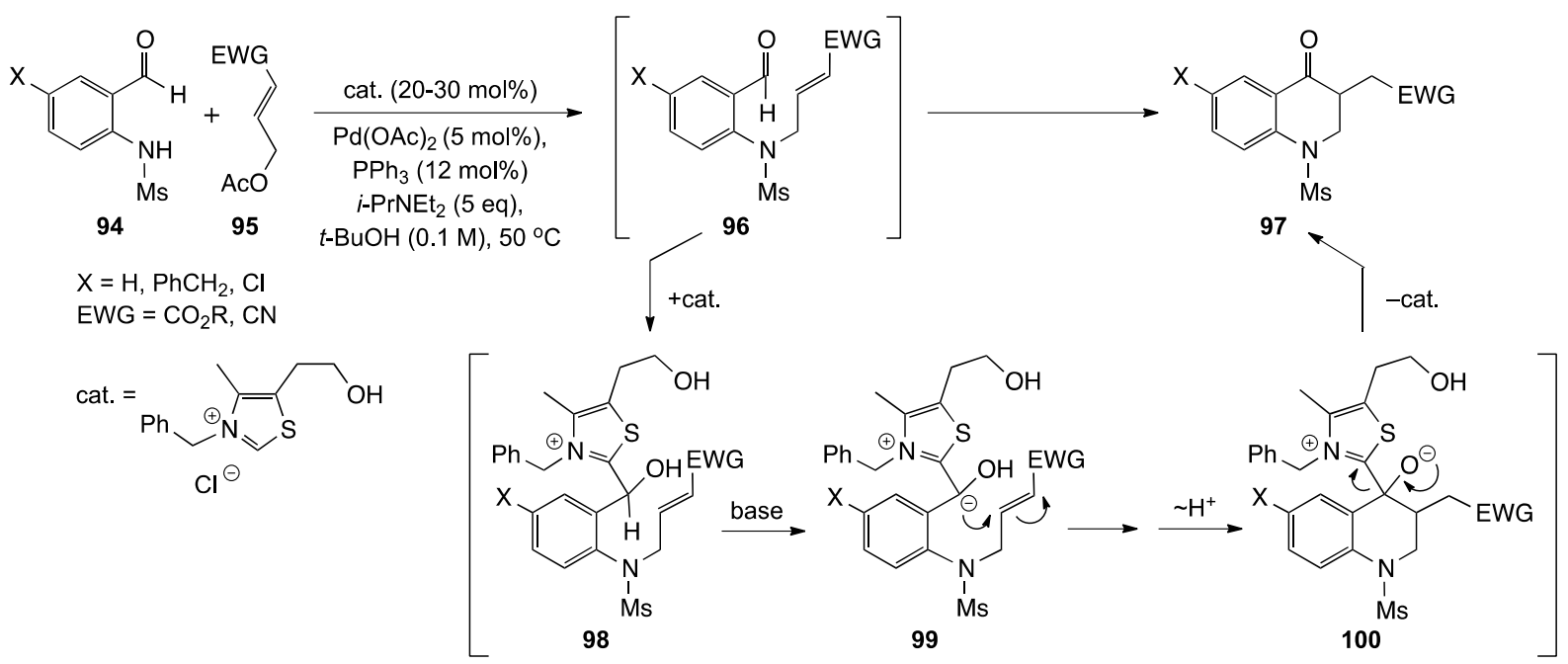

$\mathrm{Lu}$ and co-workers presented an elegant approach to asymmetric 2-aryl-2,3-dihydro-4(1H)quinolinones using a chiral tertiary amine base tethered to a bifunctional thiourea derivative [97]. In this reaction, a thiourea catalyst, derived from quinine, initially hydrogen-bonded with the $\beta$-ketoester moiety of substrate $\mathbf{1 0 1}$ to give 102. The basic quinuclidine moiety of the quinine then deprotonated the acidic sulfonamide function, and the heterocyclic ring closed by conjugate addition to the highly polarized side chain double bond to give 103. Ester hydrolysis and decarboxylation, followed by cleavage of the sulfonamide then delivered the chiral dihydroquinolinones $\mathbf{1 0 4}$. Overall yields for the sequence were $65 \%-91 \%$ with $78 \%-98 \%$ ee (Scheme 27 ).

Scheme 27. The Lu asymmetric synthesis of 2,3-dihydro-4(1H)-quinolinones.

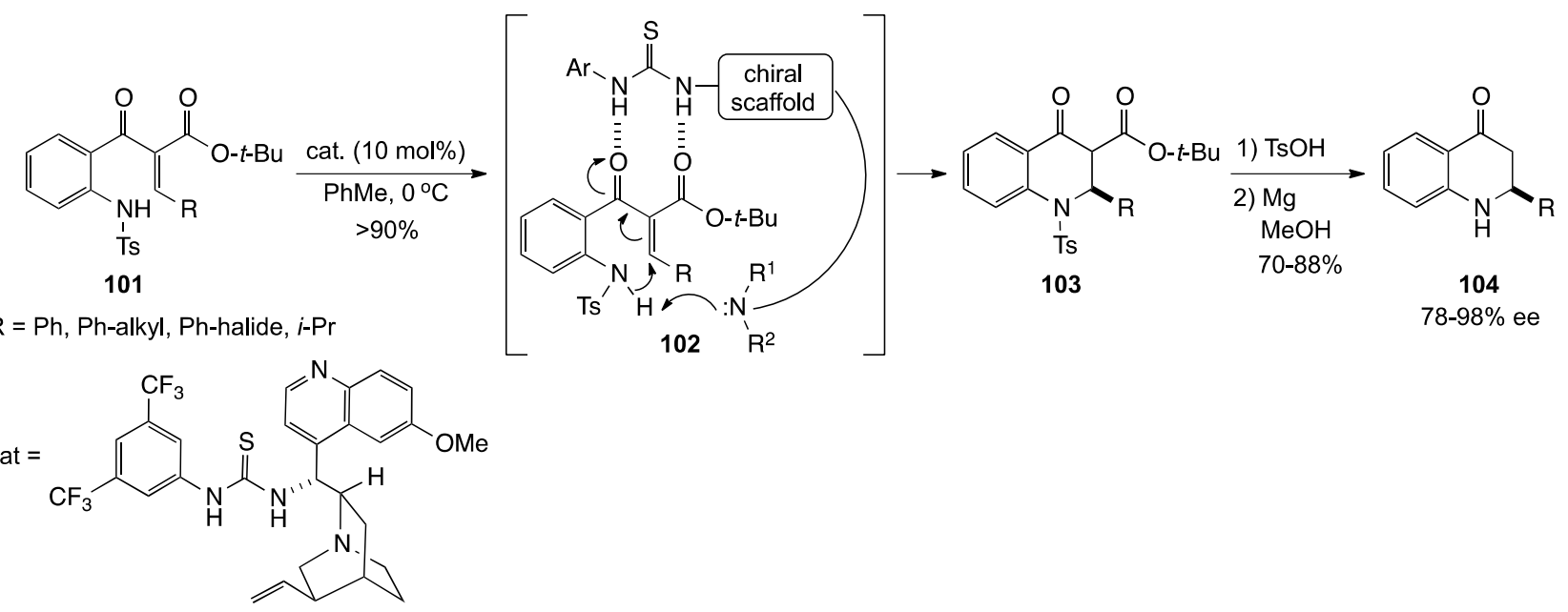

A complementary protocol for the synthesis of chiral dihydroquinolinones has been described by Pitchumani and Kanagarj [98]. The target heterocycles were produced from 2-aminoacetophenone (89) 
and aldehydes 105 in aqueous ethanol using stoichiometric per-6-amino- $\beta$-cyclodextrin (per-6-ABCD) as the base and chiral supramolecular host. The conversion occurred by initial condensation of 89 with 105 to give imines 106, followed by deprotonation of the methyl ketone by the per-6-ABCD and closure on the carbon-nitrogen double bond to give 2,3-dihydro-4(1H)-quinolinones 104 (Scheme 28). The reaction was performed using a diverse selection of aldehydes bearing electron-rich and electron-poor aromatic as well as alkyl, cycloalkyl and heterocyclic $\mathrm{R}$ groups. The reported yields ranged from $18 \%-99 \%$, and the products were obtained with $69 \%-98 \%$ ee. A major strength of this procedure was that the base was easy to prepare and could be recovered and reused without loss of activity.

Scheme 28. The Pitchumani asymmetric synthesis of 2,3-dihydro-4(1H)-quinolinones.

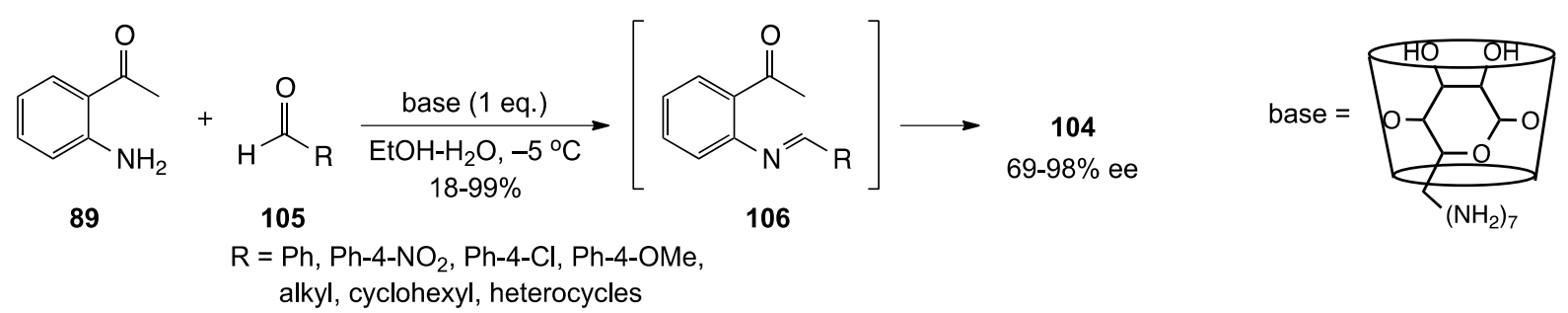

\subsection{4(1H)-Quinolinones}

The 4(1H)-quinolinones, also known as 4-quinolones, are a class of naturally occurring compounds, which display pharmacological activity for mitigating the symptoms of innumerable diseases and conditions $[99,100]$. Quinolinone alkaloids are present in many plants that were used as local remedies in ancient times. For example, compound 107, originally employed in the Middle East as an antirheumatic and a treatment for snakebites, displays significant antimicrobial activity [101]. Compound 108, a traditional skin medication from Indonesia, expresses CYP2D6 inhibitory activity that can affect the metabolism of drugs in the body [102]. Finally, compound 109, used as a Chinese folk remedy for headache and acid reflux, has recently shown broad anti-inflammatory, anticancer, and antimycobacterial properties [103-106] (Figure 4).

Figure 4. Natural products incorporating $4(1 H)$-quinolinones.
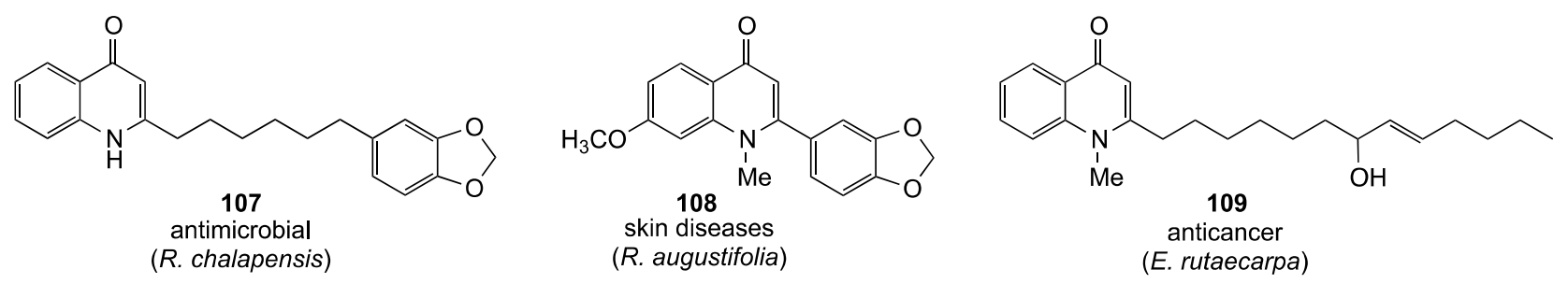

Numerous $4(1 H)$-quinolinones are also found as prominent substructures in hundreds of drugs including antibiotics [107], antimalarials [54,108], antihypertensives [109], anticancer agents [110,111], antivirals [112] and compounds to slow the progression of Alzheimer's disease [113,114]. Nalidixic acid (110), a 1st generation quinolinone antibiotic has value for the treatment of urinary bacterial infections [100]. Due to its broad spectrum activity against both Gram-negative and Gram-positive bacteria, related 2nd, 3rd and 4th generation antibiotics (more than 32 compounds), modified to contain a central fluoroquinolinone core, have been developed commercially [115]. The most 
prominent member of the 2nd generation drugs is ciprofloxacin (111), which exhibits powerful activity against many bacterial pathogens [116,117]. Further structural modification in the floxacin series gave chiral 3rd and 4th generation antibiotics 112 and 113, respectively, which are potent against a broad spectrum of bacterial strains with fewer side effects [118,119]. Fluoroquinolinones not only express potent antibiotic activity in humans, but also serve as antimicrobial and a bactericidal agents for veterinary applications [120]. Several other drugs based on the $4(1 H)$-quinolinone system include ELQ-300 (114), an antimalarial drug [108], BQCA (115), a promising medication to alleviate the effects of Alzheimer's disease [113], and Ivacaftor (116), a drug used for the treatment of cystic fibrosis $[121,122]$ (Figure 5).

Figure 5. Drug compounds incorporating 4(1H)-quinolinones.
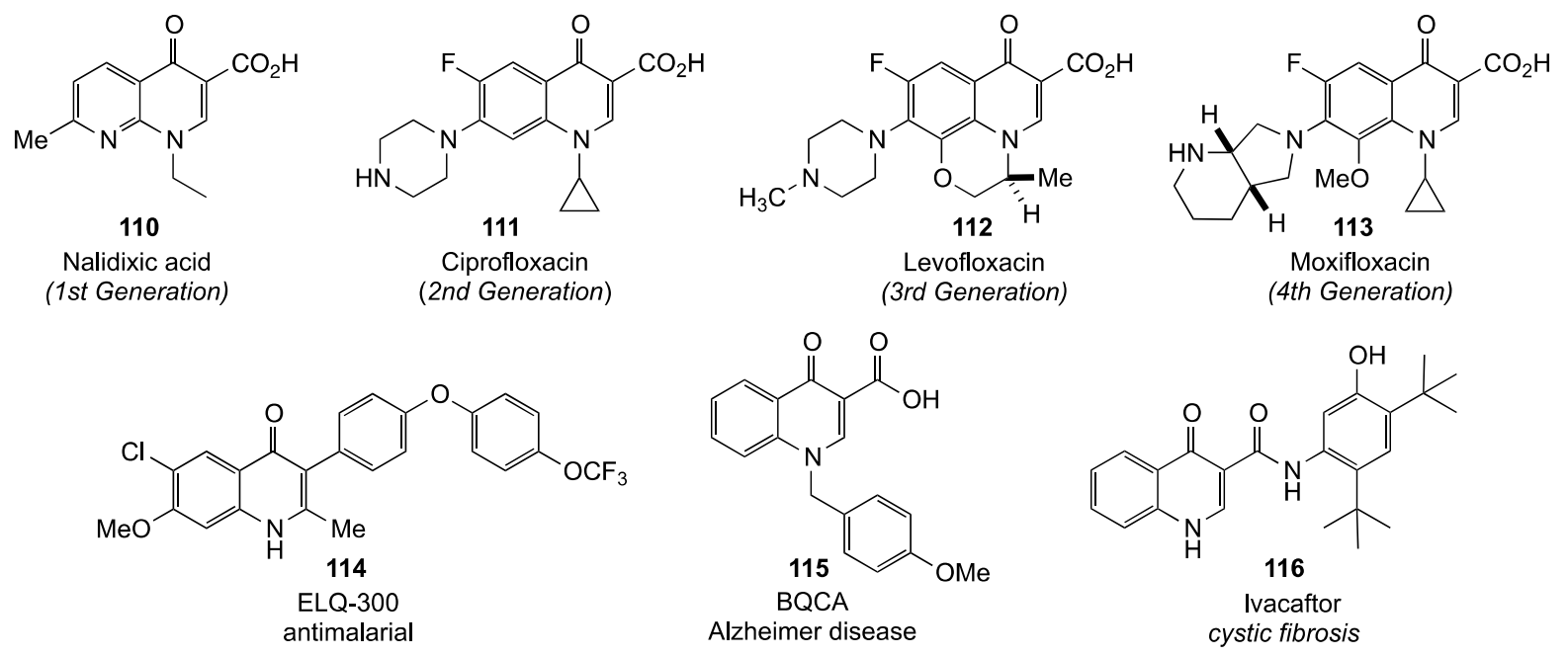

Two groups have developed syntheses of $4(1 H)$-quinolinones from enaminones such as $\mathbf{1 1 7}$, which were available via a short synthesis [123,124]. Reduction of the nitro function in 117 , using $10 \% \mathrm{Pd} / \mathrm{C}$ in ethanol containing hydrogen donors such as hydrazine hydrate or cyclohexene, initiated a domino process involving Michael addition of the amino group to the polarized double bond, followed by elimination of dimethylamine to provide heterocycles 118 in $75 \%-80 \%$ yields (Scheme 29). This addition-elimination strategy, known as the Leimgruber-Batcho reaction, has been previously used for the synthesis of indoles, but has proven equally valuable for the preparation of $4(1 H)$-quinolinones. The reaction proceeded cleanly for both singly and doubly activated side chain Michael systems.

Scheme 29. A reduction-addition-elimination sequence.

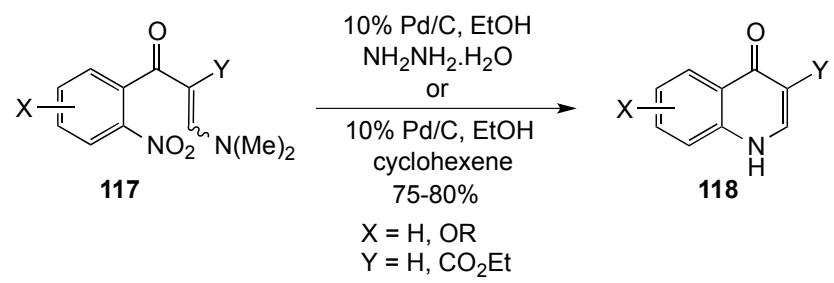

In 1983, McNab and co-workers [125] reported a synthesis of 4(1H)-quinolinone in 90\% yield from the 2-anilinomethylene derivative of Meldrum's acid 119 under flash vacuum pyrolysis conditions at $600{ }^{\circ} \mathrm{C}$ and $10^{-2}$ torr. The suggested mechanism proceeded through a 3-anilino-1,2-propadien-1-one 
intermediate 120, which tautomerized to the iminoketene 121, cyclized, and rearomatized to give the quinolinone 122 (Scheme 30). Valderrama [13] and Huang [15] independently expanded this domino approach to prepare a number of substituted 4(1H)-quinolinones with electron-donating and electron-withdrawing substituents on the aromatic ring. These investigators accomplished the conversion to quinolinones in yields of $54 \%-96 \%$ under thermolysis conditions in boiling diphenyl ether (15-20 min, 250-260 ${ }^{\circ} \mathrm{C}$ ). A later paper by the Al-Awadi group [126] further studied this transformation for a series of substrates under flash vacuum and static pyrolysis conditions. Al-Awadi noted that cyclizations under these conditions were strongly influenced by aryl substitution, with nitroarenes giving poor yields in contradiction to one result in the Huang paper [15]. Finally, this same cyclization was performed by Yadav and co-workers under microwave irradiation $\left(80{ }^{\circ} \mathrm{C}, 120 \mathrm{~min}\right)$ in the ionic liquid [BMIM]OTf (1-butyl-3-methylimidazolium trifluoromethanesulfonate) [127]. Employing this protocol, a modest selection of $4(1 H)$-quinolinones was generated in $68 \%-94 \%$ yields.

Scheme 30. 4(1H)-Quinolinones from 2-anilinomethylene derivatives of Meldrum's acid.

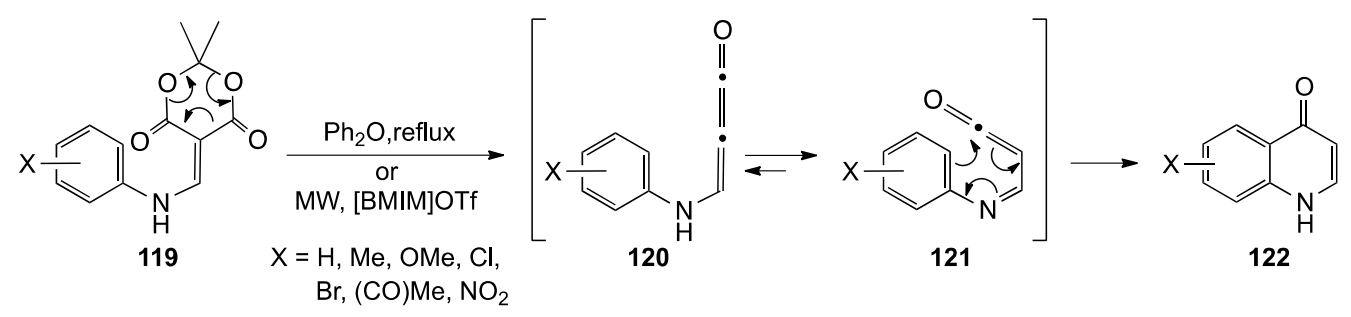

The Huang group extended their contribution to this area by using a solid phase organic synthesis strategy to prepare $4(1 H)$-quinolinones [14,128,129]. In this approach, the Merrifield resin was synthetically elaborated to attach a Meldrum's acid moiety to the polymer backbone. Further reaction with triethyl orthoformate, followed by treatment with substituted anilines, then gave the polymer-bound 2anilinomethylene Meldrum's acid derivatives 123. Subsequent thermolysis of these surface-modified polymer substrates in boiling diphenyl ether produced the desired heterocycles 124 in $47 \%-62 \%$ yields (Scheme 31). A practical application of this method is the preparation of drug candidates using a combinatorial strategy. Despite the assertion that the polymer support can be reused, there are limitations to this approach, due to the expense of the resin and the need to reassemble the Meldrum's acid moiety (three steps, 55\%-60\%) for each batch.

Scheme 31. Solid phase organic synthesis of $4(1 H)$-quinolinones.

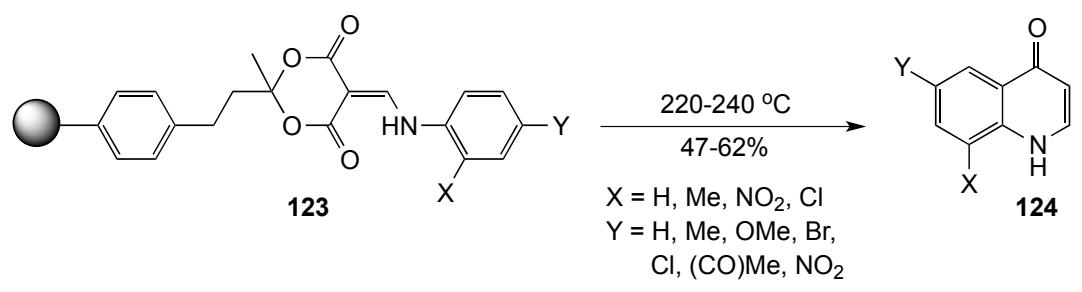

Kalinin and co-workers have reported a novel approach for the synthesis of $4(1 H)$-quinolinones using a heterocyclic Sonogashira carbonylative cross-coupling-cyclization procedure $[17,130]$. The reaction was envisioned to involve a 6-endo-dig cyclization from an alkynyl ketone formed by a $\mathrm{PdCl}_{2}\left(\mathrm{PPh}_{3}\right)_{2}$-catalyzed coupling of 2-iodoanilines 125 and terminal alkynes 126 with carbon 
monoxide to afford quinolinones 127 in 49\%-95\% yields (Scheme 32). Following the initial disclosure of this reaction, Djakovitch et al. reported an intriguing modification of the method. These researchers prepared and tested a reusable heterogeneous catalyst mixture of [PdPNP]@SBA-15 and [N]@SBA-3, which immobilized $\mathrm{PdCl}_{2}\left(\mathrm{PPh}_{3}\right)_{2}$ and the amine base, respectively, on an Santa Barbara Amorphous (SBA) silica support [131,132]. This catalyst was able to deliver the parent 2-phenyl-4(1H)quinolinone $\left(\mathrm{R}^{1}=\mathrm{R}^{2}=\mathrm{H}\right)$ with low Pd contamination in $60 \%-70 \%$ for three cycles, but gradually lost activity thereafter. This strategy merits further development, but currently, the required synthesis of the SBA silica and the multi-step protocols for preparation of the catalysts are barriers to its use.

Scheme 32. A Sonogashira carbonylative cross-coupling-cyclization reaction.

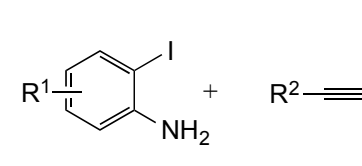

125

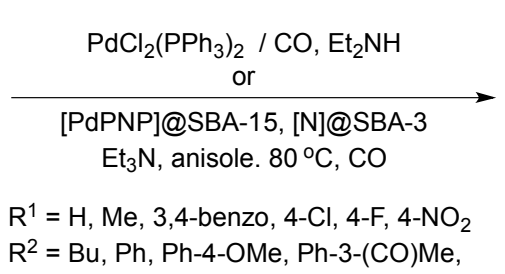

$\mathrm{Ph}-4-\mathrm{CO}_{2} \mathrm{Me}$, 1-naphthyl, piperonyl

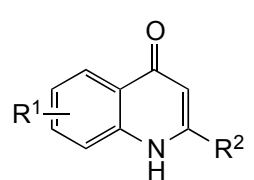

127

The Georg group has documented an alternative scheme [18] for the synthesis of a library of 2-aryl-4(1H)-quinolinones using a parallel synthesis approach. In this project, ynone substrates 128 were subjected to $\mathrm{HCl}$ in dioxane, followed by $\mathrm{K}_{2} \mathrm{CO}_{3}$ in methanol for a period of 4 days at $50{ }^{\circ} \mathrm{C}$ to yield the corresponding products 130 in 3\%-93\% yields. Although the reaction was time consuming, the process did not require strong base or high temperatures. Mechanistically, treatment of $\mathbf{1 2 8}$ with acid initially resulted in hydrolysis of the Boc group. Methanol then served as a catalytic nucleophile in a domino process triggered by conjugate addition to the triple bond under basic conditions to give 129. Subsequent to this, the ortho amino group underwent 6-endo-trig addition to the double bond, and methanol was eliminated to afford quinolinones 130 (Scheme 33).

Scheme 33. Synthesis of 2-aryl-4(1H)-quinolinones from ynones.

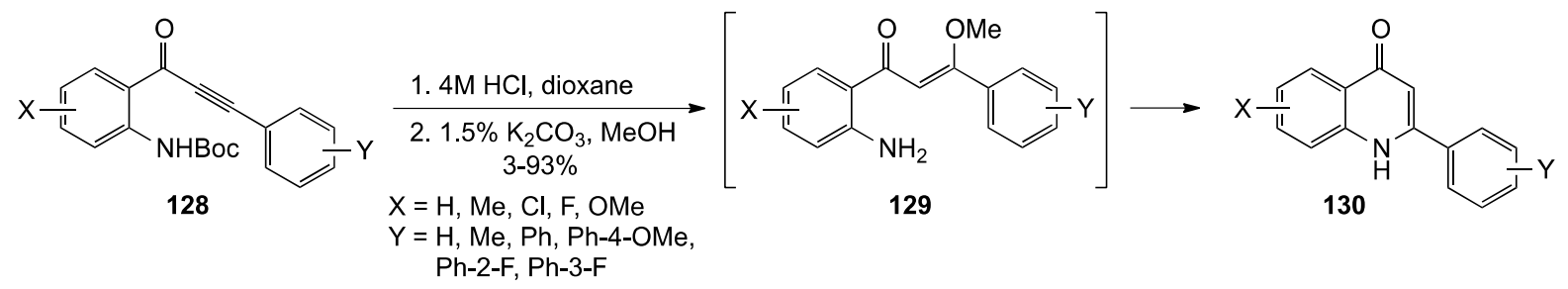

An interesting reduction-cyclization-ring opening sequence to prepare $4(1 H)$-quinolinones from azido-cyclopropyl ketones has been described by Ren and co-workers [133]. Treatment of aromatic azides 131 with $1 \mathrm{~atm}$ of $\mathrm{H}_{2}$ over catalytic $10 \% \mathrm{Pd} / \mathrm{C}$ in ethanol resulted in reduction to the aniline and ring closure on the side chain $\gamma$ carbonyl to give spirocyclopropyl imines 132. Continued exposure to hydrogenation conditions led to three-ring opening by 1,4 -addition of hydrogen to the cyclopropyl imine subunit to give the 2,3-disubstituted quinolinone derivatives $\mathbf{1 3 3}$ (Scheme 34). The reaction was reported for three examples, all of which proceeded in $>90 \%$ yield. Additional work should expand the range of viable substrates for this sequence and reveal potential applications in synthesis. 
Scheme 34. A reduction-cyclization-ring opening strategy.<smiles>O=C(O)C1(C(=O)I)CC1</smiles>

131

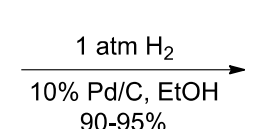

$\mathrm{R}=\mathrm{Ph}, \mathrm{Ph}-2-\mathrm{OMe}, t-\mathrm{Bu}$<smiles>[2H]C1=Nc2ccccc2C(=O)C12CC2</smiles>

132
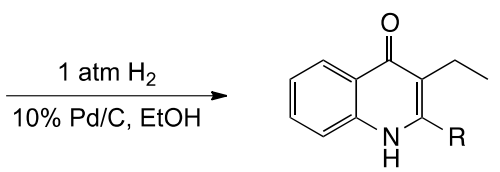

133

Finally, Skrzypek has communicated a straightforward synthesis of the parent $4(1 H)$-quinolinone by acid hydrolysis of 4-chloro-3-quinolinesulfonic acid (134) using 50\% $\mathrm{H}_{2} \mathrm{SO}_{4}$ at reflux for $3 \mathrm{~h}$ [134]. These conditions eventuated a domino process that includes (1) hydrolysis of the activated chlorine substituent and (2) desulfonation to generate $\mathbf{1 3 5}$ in 74\% yield (Scheme 35). Unfortunately, the scarcity of related structures substituted with functionality that can withstand these harsh conditions severely limits the utility of this route.

Scheme 35. A hydrolysis-desulfonation reaction.

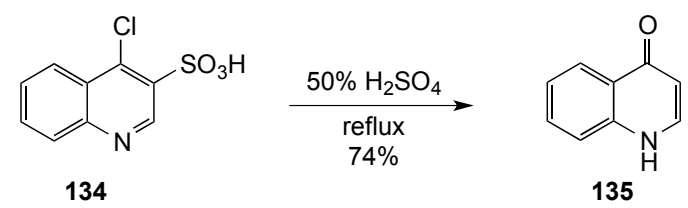

\section{Conclusions}

This brief compilation describes a wide range of domino reactions applied to the synthesis of tetrahydroquinolines and related structures over the past 20 years. Efforts are continuing in this active field to create additional approaches to these and many other heterocyclic targets that serve as pharmaceutical precursors. It is likely that future work will dramatically increase the number of accessible derivatives as well as the efficiency and selectivity of these transformations. Application of these processes to the synthesis of previously unknown molecular structures should insure that new, more potent medicinal agents are available to treat drug-resistant pathogens as well as other diseases and conditions that threaten human and animal health.

\section{Acknowledgments}

RAB wishes to thank his past and present students who are largely responsible for his contributions to this field. Their names appear as his co-authors in the reference section. RAB also wishes to acknowledge the NIH (GM 54256) and the Oklahoma Center for the Advancement of Science and Technology (HR1-035 and HR01-015) for support of his research on domino reactions over the years. Finally, the authors are very grateful to Oklahoma State University for numerous scholarships to support student research at the graduate and undergraduate levels, and to the OSU College of Arts and Sciences for funds to maintain and upgrade departmental instrumentation.

\section{Conflicts of Interest}

The authors declare no conflict of interest. 


\section{References}

1. Nicolaou, K.C.; Edmonds, D.J.; Bulger, P.G. Cascade reactions in total synthesis. Angew. Chem. Int. Ed. 2006, 45, 7134-7186.

2. Nicolaou, K.C.; Montagnon, T.; Snyder, S.A. Tandem reactions, cascade sequences, and biomimetic strategies in total synthesis. Chem. Commun. 2003, 551-564.

3. Trost, B.M. Atom economy - a challenge for organic-synthesis: Homogeneous catalysis leads the way. Angew. Chem. Int. Ed. 1995, 34, 259-281.

4. Trost, B.M. The atom economy-a search for synthetic efficiency. Science 1991, 254, 1471-1477.

5. Katritzky, A.R.; Rachwal, S.; Rachwal, B. Recent progress in the synthesis of 1,2,3,4-tetrahydroquinolines. Tetrahedron 1996, 52, 15031-15070.

6. Sridharan, V.; Suryavanshi, P.A.; Menéndez, J.C. Advances in the chemistry of tetrahydroquinolines. Chem. Rev. 2011, 111, 7157-7259.

7. Barluenga, J.; Rodriguez, F.; Fananas, F.J. Recent advances in the synthesis of indole and quinoline derivatives through cascade reactions. Chem.-Asian J. 2009, 4, 1036-1048.

8. Bunce, R.A.; Herron, D.M.; Johnson, L.B.; Kotturi, S.V. Diastereoselective synthesis of substituted tetrahydroquinoline-4-carboxylic esters by a tandem reduction-reductive amination reaction. J. Org. Chem. 2001, 66, 2822-2827.

9. Fujita, K.; Yamamoto, K.; Yamaguchi, R. Oxidative cyclization of amino alcohols catalyzed by a Cp*Ir complex. Synthesis of indoles, 1,2,3,4-tetrahydroquinolines, and 2,3,4,5-tetrahydro-1benzazepine. Org. Lett. 2002, 4, 2691-2694.

10. Bunce, R.A.; Nago, T.; Sonobe, N.; Slaughter, L.M. Benzo-fused heterocycles and carbocycles by intramolecular $\mathrm{S}_{\mathrm{N}} \mathrm{Ar}$ and tandem $\mathrm{S}_{\mathrm{N}} 2-\mathrm{S}_{\mathrm{N}} \mathrm{Ar}$ reactions. J. Heterocycl. Chem. 2008, 45, 551-557.

11. Lange, J.; Bissember, A.C.; Banwell, M.G.; Cade, I.A. Synthesis of 2,3-dihydro-4(1H)-quinolones and the corresponding 4(1H)-quinolones via low-temperature Fries rearrangement of $N$-arylazetidin-2-ones. Aust. J. Chem. 2011, 64, 454-470.

12. Gigant, N.; Gillaizeau, I. Construction of nitrogen-fused tetrahydroquinolines via a domino reaction. Org. Lett. 2012, 14, 4622-4625.

13. Cassis, R.; Tapia, R.; Valderrama, J.A. Synthesis of 4(1H)-quinolones by thermolysis of arylaminomethylene Meldrum's acid derivatives. Synth. Commun. 1985, 15, 125-133.

14. Tang, J.; Huang, X. Preparation of resin-bound bismethylene cyclic malonic acid ester and facile solid-phase synthesis of 2-alkylthio-4(1H)-quinolone and 2-alkyl-4(1H)-quinolone. Synth. Commun. 2003, 33, 3953-3960.

15. Chen, B.; Huang, X.; Wang, J. A versatile synthesis of 2-alkyl and 2-aryl-4-quinolones. Synthesis 1987, 482-483, doi:10.1055/s-1987-33427.

16. Ueda, M.; Kawai, S.; Hayashi, M.; Naito, T.; Miyata, O. Efficient entry into 2-substituted tetrahydroquinoline systems through alkylative ring expansion: Stereoselective formal synthesis of ( \pm )-martinellic acid. J. Org. Chem. 2010, 75, 914-921.

17. Kalinin, V.N.; Shostakovsky, M.V.; Ponomaryov, A.B. A new route to 2-aryl-4-quinolones via palladium-catalyzed carbonylative coupling of $o$-iodoanilines with terminal arylacetylenes. Tetrahedron Lett. 1992, 33, 373-376. 
18. Ward, T.R.; Turunen, B.J.; Haack, T.; Neuenswander, B.; Shadrick, W.; Georg, G.I. Synthesis of a quinolone library from ynones. Tetrahedron Lett. 2009, 50, 6494-6497.

19. Perry, N.B.; Blunt, J.W.; Munro, M.H.G.; Higa, T.; Sakai, R. Discorhabdin-D, an antitumor alkaloid from the sponges Latrunculia brevis and Prianos sp. J. Org. Chem. 1988, 53, 4127-4128.

20. Perry, N.B.; Blunt, J.W.; Munro, M.H.G. Cytotoxic pigments from New Zealand sponges of the genus Latrunculia-discorhabdin-A, discorhabdin-B and discorhabdin-C. Tetrahedron 1988, 44, $1727-1734$.

21. Perry, N.B.; Blunt, J.W.; McCombs, J.D.; Munro, M.H.G. Discorhabdin-C, a highly cytotoxic pigment from a sponge of the genus Latrunculia. J. Org. Chem. 1986, 51, 5476-5478.

22. Nishiyama, S.; Cheng, J.F.; Tao, X.L.; Yamamura, S. Synthetic studies on novel sulfur-containing alkaloids, prianosins and discorhabdins-Total synthesis of discorhabdin-C. Tetrahedron Lett. 1991, 32, 4151-4154.

23. Asolkar, R.N.; Schroeder, D.; Heckmann, R.; Lang, S.; Wagner-Doebler, I.; Laatsch, H. Marine bacteria XXVII. Helquinoline, a new tetrahydroquinoline antibiotic from Janibacter limosus Hel 1. J. Antibiot. 2004, 57, 17-23.

24. Satyanarayana, G.; Pflaesterer, D.; Helmchen, G. Enantioselective syntheses of tetrahydroquinolines based on iridium-catalyzed allylic substitutions: Total syntheses of $(+)$-angustureine and (-)-cuspareine. Eur. J. Org. Chem. 2011, 6877-6886.

25. Staub, G.M.; Gloer, J.B.; Wicklow, D.T.; Dowd, P.F. Aspernomine: A cytotoxic antiinsectan metabolite with a novel ring system from the sclerotia of Aspergillus nomius. J. Am. Chem. Soc. 1992, 114, 1015-1017.

26. Magomedov, N.A. Efficient construction of cyclopenta[b]quinoline core of isoschizozygane alkaloids via intramolecular formal hetero-Diels-Alder reaction. Org. Lett. 2003, 5, 2509-2512.

27. Snider, B.B.; Ahn, Y.; O’Hare, S.M. Total synthesis of ( \pm )-martinellic acid. Org. Lett. 2001, 3, 4217-4220.

28. Imanishi, S.; Kimura, T.; Arita, M. Nicainoprol. Cardiovasc. Drug Rev. 1991, 9, 223-236.

29. Galdino, D.R.P.M.; Barreto, D.M.R.M.J.; Galdino, S.L. The evolution of drugs on schistosoma treatment: Looking to the past to improve the future. Mini-Rev. Med. Chem. 2013, 13, 493-508.

30. Keck, D.; Vanderheiden, S.; Brase, S. A formal total synthesis of virantmycin: A modular approach towards tetrahydroquinoline natural products. Eur. J. Org. Chem. 2006, 2006, 4916-4923.

31. Ori, M.; Toda, N.; Takami, K.; Tago, K.; Kogen, H. Stereospecific synthesis of 2,2,3-trisubstituted tetrahydroquinolines: Application to the total syntheses of benzastatin $\mathrm{E}$ and natural virantmycin. Tetrahedron 2005, 61, 2075-2104.

32. Steinhagen, H.; Corey, E.J. A Simple convergent approach to the synthesis of the antiviral agent virantmycin. Org. Lett. 1999, 1, 823-824.

33. Back, T.G.; Wulff, J.E. A stereodivergent synthesis of virantmycin by an enzyme-mediated diester desymmetrization and a highly hindered aryl amination. Angew. Chem. Int. Ed. 2004, 43, 6493-6496.

34. Su, D.-S.; Lim, J.J.; Tinney, E.; Wan, B.-L.; Young, M.B.; Anderson, K.D.; Rudd, D.; Munshi, V.; Bahnck, C.; Felock, P.J.; et al. Substituted tetrahydroquinolines as potent allosteric inhibitors of reverse transcriptase and its key mutants. Bioorg. Med. Chem. Lett. 2009, 19, 5119-5123. 
35. Zhong, W.; Hitchcock, S.; Albrecht, B.K.; Bartberger, M.; Brown, J.; Brown, R.; Chaffee, S.C.; Cheng, Y.; Croghan, M.; Graceffa, R.; et al. Preparation of 2-Hydroxy-1,3-diaminoalkanes including Spiro Substituted Chroman Derivatives as $\beta$-Secretase Modulators and their use for Treatment Alzheimer's Disease and Related Conditions. WO2007061670A1, 2007; Chem. Abstr. 2007, 147, 52808.

36. Guo, T.; Gu, H.; Hobbs, D.W.; Rokosz, L.L.; Stauffer, T.M.; Jacob, B.; Clader, J.W. Design, synthesis, and evaluation of tetrahydroquinoline and pyrrolidine sulfonamide carbamates as $\gamma$-secretase inhibitors. Bioorg. Med. Chem. Lett. 2007, 17, 3010-3013.

37. Asberom, T.; Bara, T.A.; Clader, J.W.; Greenlee, W.J.; Guzik, H.S.; Josien, H.B.; Li, W.; Parker, E.M.; Pissarnitski, D.A.; Song, L.; et al. Tetrahydroquinoline sulfonamides as $\gamma$-secretase inhibitors. Bioorg. Med. Chem. Lett. 2007, 17, 205-207.

38. Nallan, L.; Bauer, K.D.; Bendale, P.; Rivas, K.; Yokoyama, K.; Horney, C.P.; Rao, P.P.; Floyd, D.; Lombardo, L.J.; Williams, D.K.; et al. Protein farnesyltransferase inhibitors exhibit potent antimalarial activity. J. Med. Chem. 2005, 48, 3704-3713.

39. Kubota, H.; Sugahara, M.; Furukawa, M.; Takano, M.; Motomura, D. Tetrahydroquinoline Derivatives as Cholesteryl Ester Transfer Protein Inhibitors and a Process for Preparing the Same. US20070082896A1, 2007; Chem. Abstr. 2007, 146, 500906.

40. Escribano, A.; Mateo, A.I.; Martin de la Nava, E.M.; Mayhugh, D.R.; Cockerham, S.L.; Beyer, T.P.; Schmidt, R.J.; Cao, G.; Zhang, Y.; Jones, T.M.; et al. Design and synthesis of new tetrahydroquinolines derivatives as CETP inhibitors. Bioorg. Med. Chem. Lett. 2012, 22, 3671-3675.

41. Leeson, P.D.; Carling, R.W.; Moore, K.W.; Moseley, A.M.; Smith, J.D.; Stevenson, G.; Chan, T.; Baker, R.; Foster, A.C.; Grimwood, S.; et al. 4-Amido-2-carboxytetrahydroquinolines. Structure-activity relationships for antagonism at the glycine site of the NMDA receptor. $J$. Med. Chem. 1992, 35, 1954-1968.

42. Ferranti, A.; Garuti, L.; Giovanninetti, G.; Gaggi, R.; Roncada, P.; Nardi, P. Preparation and analgesic activity of some tetrahydroquinolines and tetrahydroisoquinolines. Farmaco 1987, 42, 237-249.

43. Carling, R.W.; Leeson, P.D.; Moseley, A.M.; Smith, J.D.; Saywell, K.; Tricklebank, M.D.; Kemp, J.A.; Marshall, G.R.; Foster, A.C.; Grimwood, S. Anticonvulsant activity of glycine-site NMDA antagonists. 2. Trans 2-carboxy-4-substituted tetrahydroquinolines. Bioorg. Med. Chem. Lett. 1993, 3, 65-70.

44. Smirnova, T.A.; Gavrilov, M.Y.; Nazmetdinov, F.Y.; Kolla, V.E.; Kon'shin, M.E. Synthesis and antidepressant activity of acylhydrazides of 2-chloro- and 2-anilino-5,6,7,8-tetrahydroquinoline4-carboxylic acids. Pharm. Chem. J. 1999, 33, 370-371.

45. Oshiro, Y.; Sakurai, Y.; Sato, S.; Kurahashi, N.; Tanaka, T.; Kikuchi, T.; Tottori, K.; Uwahodo, Y.; Miwa, T.; Nishi, T. 3,4-Dihydro-2(1H)-quinolinone as a novel antidepressant drug: Synthesis and pharmacology of 1-[3-[4-(3-chlorophenyl)-1-piperazinyl]propyl]-3,4-dihydro-5-methoxy2(1H)-quinolinone and its derivatives. J. Med. Chem. 2000, 43, 177-189.

46. Scott, J.D.; Miller, M.W.; Li, S.W.; Lin, S.-I.; Vaccaro, H.A.; Hong, L.; Mullins, D.E.; Guzzi, M.; Weinstein, J.; Hodgson, R.A.; et al. Tetrahydroquinoline sulfonamides as vasopressin 1 b receptor anatgonists. Bioorg. Med. Chem. Lett. 2009, 19, 6018-6022. 
47. Moon, M.W.; Morris, J.K.; Heier, R.F.; Chidester, C.G.; Hoffmann, W.E.; Piercey, M.F.; Althaus, J.S.; von Voigtlander, P.F.; Evans, D.L.; Figur, L.M.; et al. Dopaminergic and serotonergic activities of imidazoquinolinones and related compounds. J. Med. Chem. 1992, 35, 1076-1092.

48. Holsworth, D.D.; Cai, C.; Cheng, X.-M.; Cody, W.L.; Downing, D.M.; Erasga, N.; Lee, C.; Powell, N.A.; Edmunds, J.J.; Stier, M.; et al. Ketopiperazine-based renin inhibitors: Optimization of the "C" ring. Bioorg. Med. Chem. Lett. 2006, 16, 2500-2504.

49. Holsworth, D.D.; Jalaie, M.; Belliotti, T.; Cai, C.; Collard, W.; Ferreira, S.; Powell, N.A.; Stier, M.; Zhang, E.; McConnell, P.; et al. Discovery of 6-ethyl-2,4-diaminopyrimidine-based small molecule renin inhibitors. Bioorg. Med. Chem. Lett. 2007, 17, 3575-3580.

50. Powell, N.A.; Ciske, F.L.; Cai, C.; Holsworth, D.D.; Mennen, K.; van Huis, C.A.; Jalaie, M.; Day, J.; Mastronardi, M.; McConnell, P.; et al. Rational design of 6-(2,4-diaminopyrimidinyl)1,4-benzoxazin-3-ones as small molecule renin inhibitors. Bioorg. Med. Chem. 2007, 15, 5912-5949.

51. Güller, R.; Binggeli, A.; Breu, V.; Bur, D.; Fischli, W.; Hirth, G.; Jenny, C.; Kansy, M.; Montavon, F.; Müller, M.; et al. Piperidine-renin inhibitors compounds with improved physicochemical properties. Bioorg. Med. Chem. Lett. 1999, 9, 1403-1408.

52. Baumgarth, M.; Lues, I.; Minck, K.-O.; Beier, N. Preparation of (Benzocyclylethyl)arylpiperidines and -Piperazines for Treating Arrhythmia and Tachycardia. DE4321366A1, 1995; Chem. Abstr. 1995, 122, 187620.

53. Huang, X.; Brubaker, J.; Peterson, S.L.; Butcher, J.W.; Close, J.T.; Martinez, M.; Maccoss, R.N.; Jung, J.O.; Siliphaivanh, P.; Zhang, H.; et al. Preparation of Cycloalkyl-fused Tetrahydroquinolines as CRTH2 Receptor Modulators. WO2012174176A1, 2012; Chem. Abstr. 2013, 158, 104992.

54. Sun, Y.; Zhang, Y.; Liu, M. Advanced process in research of quinoline-and related heterocycle-like antimalarial agents. Guowai Yiyao Kangshengsu Fence 2012, 33, 6-21; Chem. Abstr. 2012, 158, 690082.

55. Wang, X.-F.; Wang, S.-B.; Ohkoshi, E.; Wang, L.-T.; Hamel, E.; Qian, K.; Morris-Natschke, S.L.; Lee, K.-H.; Xie, L. N-Aryl-6-methoxy-1,2,3,4-tetrahydroquinolines: A novel class of antitumor agents targeting the colchicine site on tubulin. Eur. J. Med. Chem. 2013, 67, 196-207.

56. Madacsi, R.; Kanizsai, I.; Feher, L.Z.; Gyuris, M.; Ozsvari, B.; Erdelyi, A.; Wolfling, J.; Puskas, L.G. Aromatic sulfonamides containing a condensed piperidine moiety as potential oxidative stress-inducing anticancer agents. Med. Chem. 2013, 9, 911-919.

57. Gutierrez, M.; Carmona, U.; Vallejos, G.; Astudillo, L. Antifungal activity of tetrahydroquinolines against some phytopathogenic fungi. Z. Naturforsch. C: J. Biosci. 2012, 67, 551-556.

58. Fonseca-Berzal, C.; Merchan, A.D.R.; Romero, B.A.R.; Escario, J.A.; Kouznetsov, V.V.; Gomez-Barrio, A. Selective activity of 2,4-diaryl-1,2,3,4-tetrahydroquinolines on Trypanosoma cruzi epimastigotes and amastigotes expressing $\beta$-galactosidase. Bioorg. Med. Chem. Lett. 2013, 23, 4851-4856.

59. Wallace, O.B. Preparation of tetrahydroquinolines as selective estrogen receptor modulators. WO2002094788A1, 2002; Chem. Abstr. 2002, 137, 384759.

60. Kohno, Y.; Kojima, E. Preparation of 1,2,3,4-tetrahydroquinoline-4,8-dicarboxylates as drugs. EP403980A1, 1990; Chem. Abstr. 1991, 114, 207056. 
61. Kohno, Y.; Awano, K.; Ishizaki, T.; Kojima, E.; Kudoh, S.; Sakoe, Y.; Saito, K. Preparation of Tetrahydroquinolineacetic Acid Derivatives as Immunosuppressants. WO9218482A1, 1992; Chem. Abstr. 1993, 119, 117135.

62. Feng, L.; Huang, M.; Liu, Y.; Wu, G.; Yan, S.; Yun, H.; Zhou, M. Preparation of Novel Tetrahydroquinoline Derivatives as AMP-activated Protein Kinase Activators. US20120190677A1, 2012; Chem. Abstr. 2012, 157, 294945.

63. Bunce, R.A.; Schammerhorn, J.E.; Slaughter, L.M. Catalyst and pressure dependent reductive cyclizations for the diastereoselective synthesis of hexahydropyrrolo[1,2- $a$ ]quinoline-5-carboxylic esters. J. Heterocycl. Chem. 2006, 43, 1505-1511.

64. Bunce, R.A.; Herron, D.M.; Lewis, J.R.; Kotturi, S.V.; Holt, E.M. Diastereoselective synthesis of linear-fused tricyclic nitrogen heterocycles by a tandem reduction-reductive amination reaction. J. Heterocycl. Chem. 2003, 40, 101-106.

65. Bunce, R.A.; Schammerhorn, J.E.; Slaughter, L.M. ( \pm )-2,3-Dialkyl-1,2,3,4-tetrahydroquinoline3-carboxylic esters by a tandem reduction-reductive amination reaction. J. Heterocycl. Chem. 2007, 44, 1051-1057.

66. Bunce, R.A.; Nago, T.; Sonobe, N. ( \pm )-2-Alkyl-1,2,3,4-tetrahydroquinoline-3-carboxylic esters by a catalyst and pressure dependent tandem reduction-reductive amination reaction. J. Heterocycl. Chem. 2007, 44, 1059-1064.

67. Bunce, R.A.; Herron, D.M.; Ackerman, M.L. Aryl-fused nitrogen heterocycles by a tandem reduction-Michael addition reaction. J. Org. Chem. 2000, 65, 2847-2850.

68. Bunce, R.A.; Nammalwar, B.; Slaughter, L.M. Divergent reactivity in tandem reduction-Michael ring closures of five- and six-membered cyclic enones. J. Heterocycl. Chem. 2009, 46, 854-860.

69. Bunce, R.A.; Nago, T. 6-Nitro-1,2,3,4-tetrahydroquinolines by a tandem reductive amination-S $\mathrm{S}_{\mathrm{N}} \mathrm{Ar}$ reaction. J. Heterocycl. Chem. 2008, 45, 1155-1160.

70. Bunce, R.A.; Schammerhorn, J.E. 6-Nitro-1,2,3,4-tetrahydroquinoline-4-carboxylic Esters and 7-Nitro-3,4-dihydroquinoxaline-1(2H)-carboxylic Esters by a Tandem Reductive Amination-S $\mathrm{S}_{\mathrm{N}} \mathrm{Ar}$ Reaction. Org. Prep. Proced. Int. 2010, 42, 71-82.

71. Bunce, R.A.; Lee, E.J. Ester- and ketone-substituted ( \pm )-1-alkyl-6-nitro-1,2,3,4-tetrahydroquinolines by a tandem $\mathrm{S}_{\mathrm{N}}$ Ar-Michael reaction. J. Heterocycl. Chem. 2010, 47, 1176-1182.

72. Patti, A.; Pedotti, S. Hydrogenation of ortho-nitrochalcones over $\mathrm{Pd} / \mathrm{C}$ as a simple access to 2-substituted 1,2,3,4-tetrahydroquinolines. Tetrahedron 2010, 66, 5607-5611.

73. Liu, Y.; Wei, J.; Che, C.-M. [Fe( $\left.\left.\mathrm{F}_{20} \mathrm{TPP}\right) \mathrm{Cl}\right]$ catalyzed intramolecular $\mathrm{C}-\mathrm{N}$ bond formation for alkaloid synthesis using aryl azides as nitrogen source. Chem. Commun. 2010, 46, 6926-6928.

74. Söderberg, B.C.G.; Shriver, J.A.; Cooper, S.H.; Shrout, T.L.; Scott Helton, E.; Austin, L.R.; Odens, H.H.; Hearn, B.R.; Jones, P.C.; Kouadio, T.N.; et al. Intramolecular cyclization reactions of unsaturated amino Fischer chromium carbenes forming indoles and quinolines. Tetrahedron 2003, 59, 8775-8791.

75. Ortiz-Marciales, M.; Figueroa, D.; López, J.A.; de Jesús, M.; Vega, R. Steric and electronic effects on the reduction of $O$-silylated aromatic ketoximes with borane. Tetrahedron Lett. 2000, $41,6567-6570$. 
76. Park, K.H.; Joo, H.S.; Ahn, K.I.; Jun, K. One step synthesis of 4-ethoxy-1,2,3,4tetrahydroquinoline from nitroarene and ethanol: $\mathrm{A} \mathrm{TiO}_{2}$ mediated photocatalytic reaction. Tetrahedron Lett. 1995, 36, 5943-5946.

77. Dhiman, R.; Sharma, S.; Singh, G.; Nepali, K.; Bedi, P.M.S. Design and synthesis of aza-flavones as a new class of xanthine oxidase inhibitors. Arch. Pharm. 2013, 346, 7-16.

78. Hradil, P.; Hlavac, J.; Soural, M.; Hajduch, M.; Kolar, M.; Vecerova, R. 3-Hydroxy-2-phenyl4(1H)-quinolinones as promising biologically active compounds. Mini-Rev. Med. Chem. 2009, 9, 696-702.

79. Gill, N.S.; Kaur, A.; Arora, R.; Dhawan, V.; Bali, M. Synthetic studies of novel azaflavanone derivatives and its biological activities. Curr. Res. Chem. 2012, 4, 88-98.

80. Chandrasekhar, S.; Pushpavalli, S.N.C.V.L.; Chatla, S.; Mukhopadhyay, D.; Ganganna, B.; Vijeender, K.; Srihari, P.; Reddy, C.R.; Janaki, R.M.; Bhadra, U. Aza-flavanones as potent cross-species microRNA inhibitors that arrest cell cycle. Bioorg. Med. Chem. Lett. 2012, 22, 645-648.

81. Xia, Y.; Yang, Z.-Y.; Xia, P.; Bastow, K.F.; Tachibana, Y.; Kuo, S.-C.; Hamel, E.; Hackl, T.; Lee, K.-H. Antitumor agents. 181. Synthesis and biological evaluation of 6,7,2',3',4'-substituted1,2,3,4-tetrahydro-2-phenyl-4-quinolones as a new class of antimitotic antitumor agents. J. Med. Chem. 1998, 41, 1155-1162.

82. Stern, E.; Muccioli, G.G.; Bosier, B.; Hamtiaux, L.; Millet, R.; Poupaert, J.H.; Hénichart, J.-P.; Depreux, P.; Goossens, J.-F.; Lambert, D.M. Pharmacomodulations around the 4-oxo-1,4dihydroquinoline-3-carboxamides, a class of potent CB2-selective cannabinoid receptor ligands: Consequences in receptor affinity and functionality. J. Med. Chem. 2007, 50, 5471-5484.

83. Rasetti, V.; Rueeger, H.; Maibaum, J.K.; Mah, R.; Gruetter, M.; Cohen, N.C. Preparation of 2,9-Diamino- and 2-Amino-8-carbamoyl-4-hydroxyalkanoic Acid Amides as Renin Inhibitors. EP702004A2, 1996; Chem. Abstr. 1996, 125, 10631.

84. Ibrahim, M.M.; Deng, H.; Zvonok, A.; Cockayne, D.A.; Kwan, J.; Mata, H.P.; Vanderah, T.W.; Lai, J.; Porreca, F.; Makriyannis, A.; Malan, T.P. Activation of CB2 cannabinoid receptors by AM1241 inhibits experimental neuropathic pain: Pain inhibition by receptors not present in the CNS. Proc. Natl. Acad. Sci. USA 2003, 100, 10529-10533.

85. Mines, M.A.; Beurel, E.; Jope, R.S. Regulation of cell survival mechanisms in Alzheimer's disease by glycogen synthase kinase-3. Int. J. Alzheimers Dis. 2011, 861072, doi:10.4061/2011/ 861072.

86. Cociorva, O.; Li, B.; Szardenings, K.; Fukuda, Y.; Nomura, M.; Seto, S.; Yumoto, K.; Okada, K.; Nakamura, A. Preparation of Aminoquinolones as GSK-3 Inhibitors. WO2007106537A2, 2007; Chem. Abstr. 2007, 147, 385853.

87. Yamada, M.; Maehara, A.; Kawai, Y. Preparation of 1,2,3,4-Tetrahydro-4-oxo-3-quinolinecarboxylic Acid Esters and 2,3-Dihydro-4(1H)-quinolinones. JP2006083079A, 2006; Chem. Abstr. 2006, 144, 331280 .

88. Bunce, R.A.; Nago, T. 1-Alkyl-2,3-dihydro-4(1H)-quinolinones by a tandem Michael-S ${ }_{\mathrm{N}} \mathrm{Ar}$ annulation reaction. J. Heterocycl. Chem. 2009, 46, 623-628. 
89. Bunce, R.A.; Schammerhorn, J.E.; Sigle, J. Substituted 4-oxo-1,2,3,4-tetrahydroquinoline-3carboxylic esters by a tandem imine addition- $\mathrm{S}_{\mathrm{N}} \mathrm{Ar}$ reaction. J. Heterocycl. Chem. 2013, 50, 373-380.

90. Kano, S.; Ebata, T.; Shibuya, S. Formation of 2,3-dihydro-4(1H)-quinolones and related-compounds via Fries-type acid-catalyzed rearrangement of 1-arylazetidin-2-ones. J. Chem. Soc. Perk. Trans. 1 1980, 2105-2111.

91. Anderson, K.W.; Tepe, J.J. Trifluoromethanesulfonic acid catalyzed Friedel-Crafts acylation of aromatics with beta-lactams. Tetrahedron 2002, 58, 8475-8481.

92. Anderson, K.W.; Tepe, J.J. The first intermolecular Friedel-Crafts acylation with beta-lactams. Org. Lett. 2002, 4, 459-461.

93. Schmidt, R.G.; Bayburt, E.K.; Latshaw, S.P.; Koenig, J.R.; Daanen, J.F.; McDonald, H.A.; Bianchi, B.R.; Zhong, C.; Joshi, S.; Honore, P.; et al. Chroman and tetrahydroquinoline ureas as potent TRPV1 antagonists. Bioorg. Med. Chem. Lett. 2011, 21, 1338-1341.

94. Bunce, R.A.; Nammalwar, B. ( \pm )-2-Aryl-2,3-dihydro-4(1H)-quinolinones by a tandem reduction-Michael addition reaction. J. Heterocycl. Chem. 2011, 48, 613-619.

95. Chandrasekhar, S.; Vijeender, K.; Sridhar, C. L-Proline-catalyzed one-pot synthesis of 2-aryl-2,3-dihydroquinolin-4(1H)-ones. Tetrahedron Lett. 2007, 48, 4935-4937.

96. Nemoto, T.; Fukuda, T.; Hamada, Y. Efficient synthesis of 3-substituted 2,3-dihydro-4-quinolinones using a one-pot sequential multi-catalytic process: Pd-catalyzed allylic amination-thiazolium salt-catalyzed Stetter reaction cascade. Tetrahedron Lett. 2006, 47, 4365-4368.

97. Liu, X.; Lu, Y. Asymmetric synthesis of 2-aryl-2,3-dihydro-4-quinolones via bifunctional thiourea-mediated intramolecular cyclization. Org. Lett. 2010, 12, 5592-5595.

98. Kanagaraj, K.; Pitchumani, K. Per-6-amino- $\beta$-cyclodextrin as a chiral base catalyst promoting one-pot asymmetric synthesis of 2-aryl-2,3-dihydro-4-quinolones. J. Org. Chem. 2013, 78, 744-751.

99. Boteva, A.A.; Krasnykh, O.P. The methods of synthesis, modification, and biological activity of 4-quinolones (review). Chem. Heterocycl. Compd. 2009, 45, 757-785.

100. Basuri, T.S.; Modi, V.; Thakar, P.M. Quinolones in 2011: An update. J. Pharm. Res. 2011, 4, 1294-1297.

101. El, S.K.; Al-Said, M.S.; El-Feraly, F.S.; Ross, S.A. New quinoline alkaloids from Ruta chalepensis. J. Nat. Prod. 2000, 63, 995-997.

102. Subehan; Takahashi, N.; Kadota, S.; Tezuka, Y. Cytochrome P450 2 D6 inhibitory constituents of Lunasia amara. Phytochem. Lett. 2011, 4, 30-33.

103. Adams, M.; Kunert, O.; Haslinger, E.; Bauer, R. Inhibition of leukotriene biosynthesis by quinolone alkaloids from the fruits of Evodia rutaecarpa. Planta Med. 2004, 70, 904-908.

104. Adams, M.; Wube, A.A.; Bucar, F.; Bauer, R.; Kunert, O.; Haslinger, E. Quinolone alkaloids from Evodia rutaecarpa: A potent new group of antimycobacterial compounds. Int. J. Antimicrob. Agents 2005, 26, 262-264.

105. Huang, X.; Li, W.; Yang, X.-W. New cytotoxic quinolone alkaloids from fruits of Evodia rutaecarpa. Fitoterapia 2012, 83, 709-714.

106. Wang, X.-X.; Zan, K.; Shi, S.-P.; Zeng, K.-W.; Jiang, Y.; Guan, Y.; Xiao, C.-L.; Gao, H.-Y.; Wu, L.-J.; Tu, P.-F. Quinolone alkaloids with antibacterial and cytotoxic activities from the fruits of Evodia rutaecarpa. Fitoterapia 2013, 89, 1-7. 
107. Tang, Y.; Ding, Y.; Liu, R.; Zhu, X. Progress in synthesis of quinolones as antibacterial agents. Yaoxue Jinzhan 2012, 36, 433-444; Chem. Abstr. 2013, 158, 246149.

108. Nilsen, A.; LaCrue, A.N.; White, K.L.; Forquer, I.P.; Cross, R.M.; Marfurt, J.; Mather, M.W.; Delves, M.J.; Shackleford, D.M.; Saenz, F.E.; et al. Quinolone-3-diarylethers: A new class of antimalarial drug. Sci. Transl. Med. 2013, 5, 177 ra37.

109. Davies, R.V.; Robinson, K. Preparation of 1-alkyl-3-(alkylthio)-4-quinolones and analogs as antihypertensive agents. WO9102724A1, 1991; Chem. Abstr. 1991, 115, 92095.

110. Mugnaini, C.; Pasquini, S.; Corelli, F. The 4-quinolone-3-carboxylic acid motif as a multivalent scaffold in medicinal chemistry. Curr. Med. Chem. 2009, 16, 1746-1767.

111. Wang, H.; Sun, Y.; Zhou, Y.; You, Q. Advances in privileged structure 4-quinolones as antitumor agents research. Zhongguo Yaowu Huaxue Zazhi 2012, 22, 59-67; Chem. Abstr. 2012, 157, 165392.

112. Sato, M.; Kawakami, H.; Motomura, T.; Aramaki, H.; Matsuda, T.; Yamashita, M.; Ito, Y.; Matsuzaki, Y.; Yamataka, K.; Ikeda, S.; et al. Quinolone carboxylic acids as a novel monoketo acid class of human immunodeficiency virus type 1 integrase inhibitors. J. Med. Chem. 2009, 52, 4869-4882.

113. Mistry, S.N.; Valant, C.; Sexton, P.M.; Capuano, B.; Christopoulos, A.; Scammells, P.J. Synthesis and pharmacological profiling of analogues of benzyl quinolone carboxylic acid (BQCA) as allosteric modulators of the M1 muscarinic receptor. J. Med. Chem. 2013, 56, 5151-5172.

114. Otsubo, K.; Yamauchi, T.; Ochi, Y. Preparation of Quinolone Compounds for Treating Neurological Diseases, Diseases Induced by Mitochondrial Dysfunction, Cardiovascular Disease, and Other Disorders. WO2010064735A1, 2010; Chem. Abstr. 2010, 153, 37063.

115. Oliphant, C.M.; Green, G.M. Quinolones: A comprehensive review. Am. Fam. Physician 2002, 65, 455-464.

116. Sanchez, J.P.; Domagala, J.M.; Hagen, S.E.; Heifetz, C.L.; Hutt, M.P.; Nichols, J.B.; Trehan, A.K. Quinolone antibacterial agents. Synthesis and structure-activity relationships of 8-substituted quinoline-3-carboxylic acids and 1,8-naphthyridine-3-carboxylic acids. J. Med. Chem. 1988, 31, 983-991.

117. Sharma, P.C.; Jain, A.; Jain, S.; Pahwa, R.; Yar, M.S. Ciprofloxacin: Review on developments in synthetic, analytical, and medicinal aspects. J. Enzyme Inhib. Med. Chem. 2010, 25, 577-589.

118. Hermecz, I. Recent development in the chemistry of bicyclic 6-6 systems containing one bridgehead nitrogen atom and one extra heteroatom and their benzologs: An update. Adv. Heterocycl. Chem. 2011, 104, 1-126.

119. Barrett, J.F. Moxifloxacin (Bayer). Curr. Opin. Invest. Drugs 2000, 1, 45-51.

120. Lees, P.; Shojaee, A.F. Rational dosing of antimicrobial drugs: Animals versus humans. Int. J. Antimicrob. Agents 2002, 19, 269-284.

121. Raju, S.V.; Rowe, S.M. Ivacaftor: CFTR potentiator treatment of cystic fibrosis. Drugs Future 2012, 37, 167-174.

122. Schwarz, C. Drug therapy for cystic fibrosis. Arzneimitteltherapie 2013, 31, 80-88.

123. Bunce, R.A.; Nammalwar, B. 4(1H)-Quinolinones by a tandem reduction-addition-elimination reaction. Org. Prep. Proced. Int. 2010, 42, 557-563. 
124. Tois, J.; Vahermo, M.; Koskinen, A. Novel and convenient synthesis of 4(1H)-quinolones. Tetrahedron Lett. 2005, 46, 735-737.

125. Gordon, H.J.; Martin, J.C.; McNab, H. Thermal functionalization of nitrogen substituents: Formation of dihydropyrrol-3-ones, quinolin-4-ones, and enaminoenaminones by gas-phase hydrogen transfer reactions. J. Chem. Soc. Chem. Commun. 1983, 957-958.

126. Al-Awadi, N.A.; Abdelhamid, I.A.; Al-Etaibi, A.M.; Elnagdi, M.H. Gas-phase pyrolysis in organic synthesis: Rapid green synthesis of 4-quinolinones. Synlett 2007, 2205-2208, doi:10.1055/s-2007-985573.

127. Yadav, A.K.; Sharma, G.R.; Dhakad, P.; Yadav, T. A novel ionic liquid mediated synthesis of 4(1H)-quinolones, $5 H$-thiazolo[3,2-a]pyrimidin-5-one and 4H-pyrimido[2,1-b]benzothiazol-4ones. Tetrahedron Lett. 2012, 53, 859-862.

128. Huang, X.; Liu, Z. Preparation of a resin-bound cyclic malonic ester and a facile solid-phase synthesis of 4(1H)quinolones. Tetrahedron Lett. 2001, 42, 7655-7657.

129. Huang, X.; Liu, Z. Solid-phase synthesis of 4(1H)-quinolone and pyrimidine derivatives based on a new scaffold polymer-bound cyclic malonic acid ester. J. Org. Chem. 2002, 67, 6731-6737.

130. Torii, S.; Okumoto, H.; Xu, L.H.; Sadakane, M.; Shostakovsky, M.V.; Ponomaryov, A.B.; Kalinin, V.N. Syntheses of chromones and quinolones via Pd-catalyzed carbonylation of $o$-iodophenols and anilines in the presence of acetylenes. Tetrahedron 1993, 49, 6773-6784.

131. Genelot, M.; Dufaud, V.; Djakovitch, L. Heterogeneous metallo-organocatalysis for the selective one-pot synthesis of 2-benzylidene-indoxyl and 2-phenyl-4-quinolone. Tetrahedron 2011, 67, 976-981.

132. Genelot, M.; Bendjeriou, A.; Dufaud, V.; Djakovitch, L. Optimized procedures for the one-pot selective syntheses of indoxyls and 4-quinolones by a carbonylative Sonogashira/cyclization sequence. Appl. Catal. A 2009, 369, 125-132.

133. Yang, W.; Xu, L.; Chen, Z.; Zhang, L.; Miao, M.; Ren, H. Ru-catalyzed synthesis of dihydrofuroquinolines from azido-cyclopropyl ketones. Org. Lett. 2013, 15, 1282-1285.

134. Skrzypek, L. Azinyl sulfides. XLIX. Synthesis of 4-amino-3-quinolinesulfonic acids and 4-aminoquinolines. Heterocycles 1998, 48, 71-78.

(C) 2013 by the authors; licensee MDPI, Basel, Switzerland. This article is an open access article distributed under the terms and conditions of the Creative Commons Attribution license (http://creativecommons.org/licenses/by/3.0/). 